\title{
How do college/university teacher misbehaviors influence student cognitive learning, academic self-efficacy, motivation, and curiosity?
}

Sara R. Banfield

West Virginia University

Follow this and additional works at: https://researchrepository.wvu.edu/etd

\section{Recommended Citation}

Banfield, Sara R., "How do college/university teacher misbehaviors influence student cognitive learning, academic self-efficacy, motivation, and curiosity?" (2009). Graduate Theses, Dissertations, and Problem Reports. 3514.

https://researchrepository.wvu.edu/etd/3514

This Dissertation is protected by copyright and/or related rights. It has been brought to you by the The Research Repository @ WVU with permission from the rights-holder(s). You are free to use this Dissertation in any way that is permitted by the copyright and related rights legislation that applies to your use. For other uses you must obtain permission from the rights-holder(s) directly, unless additional rights are indicated by a Creative Commons license in the record and/ or on the work itself. This Dissertation has been accepted for inclusion in WVU Graduate Theses, Dissertations, and Problem Reports collection by an authorized administrator of The Research Repository @ WVU.

For more information, please contact researchrepository@mail.wvu.edu. 
How do college/university teacher misbehaviors influence student cognitive learning, academic self-efficacy, motivation, and curiosity?

\author{
Sara R. Banfield \\ Dissertation submitted to the \\ College of Human Resources and Education \\ at West Virginia University \\ in partial fulfillment of the requirements \\ for the degree of \\ Doctor of Education \\ in \\ Educational Psychology \\ Daniel Hursh, Ph.D., Chair \\ Sebastian R. Diaz, Ph.D. \\ Matthew M. Martin, Ph.D. \\ Melanie Booth-Butterfield, Ph.D. \\ Maria Brann, Ph.D.
}

Department of Technology, Learning and Culture

Morgantown, West Virginia

(C) 2009

Keywords: Teacher Misbehavior; Cognitive Learning; Academic Self-Efficacy; Motivation; Curiosity Copyright 2009 Sara R. Banfield 
How do college/university teacher misbehaviors influence student cognitive learning, academic self-efficacy, motivation, and curiosity?

Sara R. Banfield

\begin{abstract}
The purpose of this research was to examine the relationship between teacher misbehaviors and a variety of outcome variables, including cognitive learning, motivation, curiosity, and academic self-efficacy. Research has yet to directly address how teacher misbehaviors affect cognitive learning. It is important to assess actual learning as opposed to perceived learning to truly measure how a students' learning is influenced by the negative behaviors. Motivation, curiosity, and academic self-efficacy have been found to have a positive relationship with learning. When misbehaviors were present cognitive learning and motivation were not found to be significantly influenced by misbehaviors. Academic self-efficacy and curiosity were found to be negatively influenced by specific teacher misbehavior. Further discussion and implications were discussed.
\end{abstract}




\section{Table of Contents}

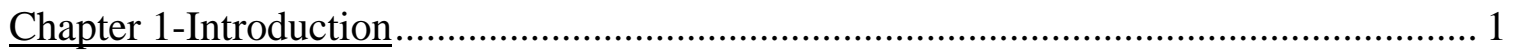

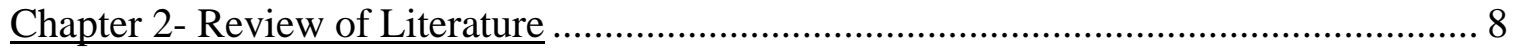

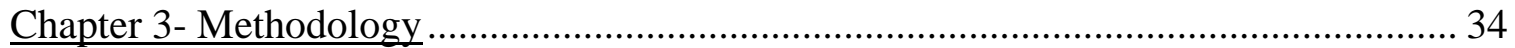

Chapter 4- Results............................................................41

Chapter 5- Discussion........................................................46

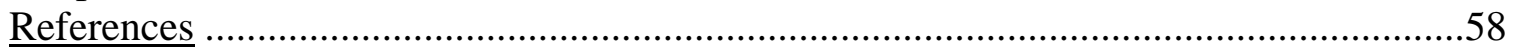

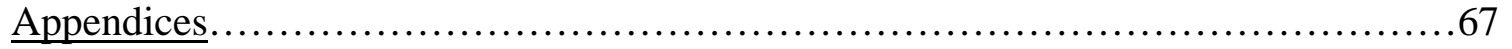

Condition A: Good Teacher.............................................67

Condition B: Incompetent Teacher.......................................... 71

Condition C: Indolent Teacher............................................. 74

Condition D: Offensive Teacher........................................... 78

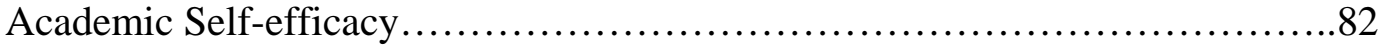

Curiosity.............................................................. 83

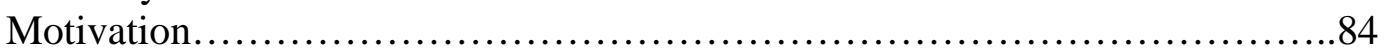

Cognitive Test............................................................ 85

Manipulation Check...................................................88 


\section{Acknowledgements}

This dissertation could not have been written without Dr. Dan Hursh who not only served as my supervisor but also encouraged and challenged me throughout my academic program. He and the other faculty members, Dr. Maria Brann, Dr. Melanie Booth-Butterfield, Dr. Sebastian Diaz, and Dr. Matthew Martin, patiently guided me through the dissertation process, never accepting less than my best efforts. Thank you to both Dr. Diaz and Dr. Martin for all their help with my results section and statistical questions. I thank them all.

My very special thanks to the two people whom I owe everything I am today, my father and mother, Richard and Sally Banfield. Their unwavering faith and confidence in my abilities and in me is what has shaped me to be the person I am today. They showed me the true worth of hard work. Helping me succeed and participating in my dissertation. Mom, thank you for being my instructor and reading every version of my dissertation. Dad, thank you for correcting my grammar and adding my commas for me. Thank you for everything. I would also like to thank my sister Anne and my brother Andrew for their love and support. Finally, I would like to take the opportunity to thank all my teachers. 


\section{Chapter 1-Introduction}

When talking about misbehavior in the classroom, most people think of students who misbehave by disrupting, not following instruction, bullying, fighting, etc. While students’ misbehavior is a problem, they are not the only individuals who can misbehave in the classroom. Research has found that teachers can also be to blame for misbehavior in the classroom (Kearney, Plax, \& Allen, 2002). They may enact behaviors themselves that may harm cognitive learning, affective learning, and the classroom climate (Banfield, McCroskey, \& Richmond, 2006; Dolin, 1995; Kearney, Plax, Hays, \& Ivey, 1991; Thweatt, \& McCroskey, 1996, 1997, 1998). The goal of this study was to examine students' responses to instruction that includes misbehaviors that may negatively affect students.

Much of the research on teacher misbehaviors measures affective learning, perceived cognitive learning, or learning loss. What is missing is a direct measurement of cognitive learning and how misbehaviors may directly affect the learning of students. The purpose of this research was to measure the students' cognitive learning in an actual teaching situation. This is important to measure because the overall goal of instruction is to increase cognitive learning. If misbehaviors get in the way of learning, then they are issues that should be addressed by every teacher. Motivation, academic self-efficacy, and curiosity were also examined along with cognitive learning. These variables drive students' learning and could affect their desire to learn the content. The current study began to address how these variables were negatively affected when a specific type of teacher misbehavior was present. The first variable that will be discussed is teacher misbehavior. The focus of the study was on the impact of teacher misbehavior on students’ responses. 
Teacher Misbehavior

Many researchers have examined teacher misbehaviors (Banfield, McCroskey, \& Richmond, 2006; Dolin, 1995; Thweatt, \& McCroskey, 1996, 1997, 1998). Kearney, Plax, Hays, and Ivey (1991) first examined and identified teacher misbehavior. The authors had students identify behaviors that they would consider misbehaving on the teacher's part. They determined that most misbehaviors fall under three categories. These categories have been identified as incompetent, indolent, and offensive behaviors (Kearney, et al. 1991). Each category holds a unique group of behaviors.

The category of incompetence deals with basic skills of teaching that instructors should possess. These misbehaviors could include the use of monotone, confusing instructions, unreasonable expectations, etc. (Kearney, et al., 1991). These behaviors demonstrate a lack of competence; this can be either in a teacher's knowledge of subject matter or his/her teaching skills.

The second type of misbehavior is indolence. Indolent behaviors are represented by teachers' disregard for the students. Examples of these behaviors would include missing class, rushing through class periods so they can leave early, returning papers to students late, etc. (Kearney, et al, 1991). These behaviors represent laziness in teacher behavior.

The third category of misbehavior is offensiveness. These misbehaviors are behaviors that teachers enact that show a general tendency to abuse the students verbally. Examples of these behaviors would include humiliating, embarrassing, and insulting students (Kearney, et al, 1991). The behaviors are offensive because they are abusive and they personally attack the student. These three categories make up the concept of teacher misbehaviors. 
Overall, misbehaviors have been found to be negative to students (Kearney, Plax, Hays, \& Ivey, 1991). Because teacher misbehaviors have been found to harm affective learning as well as perceived cognitive learning, actual cognitive learning should be examined. Cognitive learning is central to the teaching process; if misbehaviors harm this learning, these behaviors would be perceived as more important in the teaching situation.

\section{Cognitive Learning}

Learning is the ultimate goal for any teaching situation. Cognitive learning is the student knowledge that teachers test. This is the information that they are trying to pass on to their students. This is considered a behavioral component because this is often measured to ensure learning has occurred. Researchers have suggested five families of cognitive learning: content understanding, collaboration, communication, problem solving, and metacognition (Klein, O’Neil, Dennis, \& Baker, 1997). When students understand the subject it is considered content understanding. Collaboration is learning to work with others in a team. Communication is the ability to successfully convey ideas to others. Problem solving learning allows students to apply what they have learned to solve problems. Metacognition is learning that allows students to be aware of their cognition and their thought process (Klein, et. al., 1997). In this study, cognitive learning will focus on content understanding.

When talking about misbehaviors, the most negative outcome that can happen is for teachers to deter learning. Research has yet to directly test cognitive learning when misbehaviors are present. Researchers have tested this type of learning by asking questions like "would your learning be affected by these misbehaviors” (Dolin, 1995). While this is beginning to address cognitive learning, actual learning is not being measured. 
Cognitive learning can be influenced by the other variables addressed in this research: motivation, academic self-efficacy, and curiosity. Since learning is the ultimate goal, researchers must address these concepts and discover more ways to make sure students have the best learning environment. If misbehaviors are present, they may reduce these drives in students and reduce their overall desire for cognitive learning. The first variable that will be addressed is motivation.

\section{Motivation}

Hilgard, Atkinson, and Atkinson offer a definition in Huang (2003, p. 90) for motivation, defining it as a "cluster of factors that energizes behavior and gives it direction". There are two types of motivation: state and trait. State motivation "exists when student engagement in a particular activity is guided by the intention of acquiring the knowledge or mastering the skill that the activity is designed to teach” (Brophy, 1987, p. 40). Trait motivation has been defined as “a student’s enduring disposition to strive for content knowledge and skill mastery in learning situations” (Brophy, p. 40). Both state and trait motivation can influence whether a student is going to seek out environments such as career services to deal with preparations for graduation. Student Academic Self-Efficacy

Academic self-efficacy has been conceptualized by researchers as the students’ own beliefs that they are capable of completing their schoolwork successfully (Ryan, Gheen, \& Midgley, 1998; Schunk, 1991). If individuals have academic self-efficacy, they feel that they are in control of their schoolwork and they can complete anything. If a teacher is misbehaving, the students' self-efficacy toward their learning should be affected. Academic self-efficacy is one aspect of affective responses that students can have in an instructional situation; another is 
curiosity.

\section{Student Curiosity}

Curiosity has been defined as "the positive emotional-motivational system oriented toward the recognition, pursuit, and self-regulation of novel and challenging information and experiences” (Kashdan \& Roberts, 2004). State curiosity was being examined in this study. This type of curiosity is situation-based and can change over time (Kashdan \& Roberts, 2004). State curiosity can also vary as a function that enables individuals or inhibits individuals in different situations (Kashdan \& Robert, 2004). Researchers have found that individuals will explore or use curiosity behavior when a situation is new, unique, or they experience something that they don’t understand and want further information (Minuchin, 1971). In education, curiosity is valuable because it drives students to seek out more learning. More research is needed to examine exactly how curiosity is affected in an instructional situation.

\section{Rationale}

A review of previous research reveals that a void is present in research that investigates the relationship between teacher misbehaviors and students' cognitive learning responses. The purpose of this dissertation was to begin to fill the void of research in these areas by examining the impact of teacher misbehavior on students’ cognitive learning, motivation, academic selfefficacy, and curiosity. While some aspects of these responses have been addressed, the method of addressing these issues has been limited to surveys and quasi-experiments. The goal of this research was to directly manipulate the misbehavior and measure the responses of the participants. Not only was the goal to fill a void that previous research has missed, but also provide new insight into how students react to teacher misbehaviors. Therefore, the following 
research problem was put forth and four hypotheses were presented:

Research Problem: Are student responses of cognitive learning, motivation, academic selfefficacy, and curiosity influenced by teacher misbehaviors?

Many researchers (Banfield, McCroskey, \& Richmond, 2006; Dolin, 1995; Kearney, Plax, Hays, \& Ivey, 1991) previously claimed that cognitive learning would be negatively affected by teacher misbehavior, but none of them actually manipulate cognitive learning. The hypothesis has a negative direction because previous research indicates that when teacher misbehaviors are present, learning is reduced and thus would be negatively influenced (Banfield, et al., 2006; Dolin, 1995). This pattern should be found in the current research based on the supporting evidence of previous research. Thus, the following hypotheses were offered. $\mathrm{H} 1_{\mathrm{a}}$ : Students’ cognitive learning will be negatively influenced by teacher misbehaviors. Students’ learning is influenced by many variables. Researchers have defined three variables that are perceived to be important to this learning: motivation, academic self-efficacy, and curiosity. Teacher misbehavior research has yet to address these variable outcomes. Motivation (Kerssen-Griep, Hess, \& Trees, 2003), academic self-efficacy (Schunk, 1991), and curiosity (Kashdan \& Roberts, 2004) have been considered key components by researchers and educators in influencing students' learning. Since these behaviors (or variables) are considered to be very important to student learning, research needs to address how teachers’ behaviors can actually negatively influence these variables. Once again, these hypotheses were posited in a directional nature. The reason they are directional is that all research regarding teacher misbehaviors indicates that it has a negative impact on students' educational experience. Since motivation, academic self-efficacy, and curiosity were part of the educational experience, these 
behaviors should be negatively influenced. Thus, the following three hypotheses are presented. $\mathrm{H} 1_{\mathrm{b}}$ : Students’ motivation will be negatively influenced by teacher misbehaviors. $\mathrm{H} 1_{\mathrm{c}}$ : Students’ academic self-efficacy will be negatively influenced by teacher misbehaviors.

$\mathrm{H} 1_{\mathrm{d}}$ : Students’ curiosity will be negatively influenced by teacher misbehaviors. According to previous research, students have reported offensive teachers to have the most negative influence on their educational experience (Banfield, McCroskey, \& Richmond, 2006; Dolin, 1991). While this has been found in research that indirectly measures cognitive learning and other variables, a direct manipulation has not occurred. Other research has found other teacher misbehaviors to be more prominent but not necessarily as negative (Zhang, 2007). Based on these previous findings the following hypothesis was offered.

H2: Offensive teachers will have the most negative outcome on students, followed by incompetent and indolent. 


\section{Chapter 2- Review of Literature}

This study examined how students' drive for learning, specifically cognitive learning, is affected when misbehaviors are introduced. Students are negatively affected by teacher misbehavior and more research is needed to fully understand the relationship between teacher misbehavior and student outcomes. The following section will address previous research in all mentioned areas. The first area of discussion and the focus of this study is teacher misbehavior.

Kearney, Plax, Hays, and Ivey (1991) were the first researchers to fully conceptualize the idea of teacher misbehaviors. The purpose of their first study was to establish misbehaviors that teachers committed as reported by undergraduate students. Participants in the first study were 254 undergraduate students. These participants identified one thousand seven hundred misbehaviors. These behaviors were then categorized into 28 different teacher misbehavior types. The most frequently cited types were sarcasm and putdowns, absences, strays from subject, unfair testing, and boring lectures. From these 28 different types of behaviors the second study was conducted to determine if there were meaningful structures (Kearney, et al. 1991). In this study 261 students participated. All but 7 of the 28 categories were reduced into three dimensions: incompetence, offensiveness, and indolence (Kearney, et al.). Each category holds a unique group of behaviors.

The category of incompetence deals with basic skills of teaching that instructors should possess. These misbehaviors could include the use of monotone, confusing instructions, unreasonable expectations, etc (Kearney, et al, 1991). These behaviors demonstrate a lack of competence that can be either in teachers' knowledge of subject matter or related to their ability to actually teach. 
The second type of misbehavior is indolence. Indolent behaviors are represented by teachers' disregard for the students. Examples of these behaviors would include missing class, rushing through class periods so they can leave early, returning papers to students late, etc (Kearney, et al, 1991). These behaviors represent laziness in teacher behavior.

The third category of misbehavior is offensiveness. These misbehaviors are actions when teachers show a general tendency to abuse the students verbally. Examples of these behaviors would include humiliating, embarrassing, insulting students, etc (Kearney, et al, 1991). The behaviors are offensive and abusive; they personally attack the student. These three categories make up the concept of teacher misbehaviors.

While this study was the first research study to address teacher misbehaviors, there are some limitations to this study. The first limitation of this research was that it utilized only college students. Other individuals such as high school, middle school, or elementary school teachers need to be addressed to fully understand what behaviors students perceive to be teachers' misbehaviors at each level. The authors were able to develop a typology of potential college/university teacher misbehaviors that researchers can use as a starting point for this research.

Student reactions to misbehaviors. Dolin (1995) examined how teacher misbehavior on the college level affected student learning, student resistance, and the liking of instructors and content. While the popular belief was that college instructors misbehave on a regular basis, results indicated that few misbehaviors occur and the misbehaviors that do occur seem to be the least harmful (Dolin, 1995). When misbehaviors are present, even if they occur infrequently, they are detrimental to the students in a very negative way; students perceive that they are 
learning less, affective learning is reduced, and the teacher is perceived as less immediate (Dolin). When teachers misbehaved students reported liking the teacher less. Students also resisted more when teacher misbehaviors were present. This means that students were negatively affected when misbehaviors were present in the learning environment (Dolin).

Results also indicate that there are characteristics or variables that teachers have that can lead to misbehavior being perceived by students. Teachers who misbehave are perceived to have lower nonverbal immediacy and lower responsiveness. High communication apprehension in teachers was found to be related to students’ perceptions of teacher misbehaviors. Results also demonstrate that if a teacher is more extroverted, it is less likely students will see that teacher as misbehaving (Dolin, 1995).

Zhang (2007) also examined how students were influenced by teacher misbehavior. The researcher examined the misbehaviors in terms of how they demotivate students. Participants in this study included 659 undergraduate students from four different cultures: United States, China, Germany, and Japan. From the U.S. came 164 participants, 197 from China, 181 from Germany, and 153 from Japan. Similar to other research (Dolin, 1995), Zhang first found that teachers across cultures were perceived to infrequently misbehave. Results also indicated that incompetence was reported to be the most common misbehavior across all cultures. Finally, participants reported demotivation would occur if teacher misbehaviors were enacted.

Kelsey, Kearny, Plax, Allen, and Ritter (2004) explored how students understand teacher misbehaviors using attribution theory. Attribution theory examines the process we go through to create or interpret causes of others’ behaviors as well as our own (Kelley, \& Michela, 1980). From two samples, a total of 619 participants were involved in this study (Kelsey, Kearny, Plax, 
Allen, \& Ritter, 2004). Data was collected that was both qualitative and quantitative. Qualitative data examines the types of attributions students made about teacher misbehavior. This resulted in two common categories: internal attribution and external attribution. Results indicate that students recognize when teachers misbehave and attribute misbehaviors to the teachers' internal attribution rather than external factors or themselves (Kelsey, et al. 2004). Teachers who utilize immediacy still have this attribution applied to them (Kelsey, et al.). If the teacher misbehaves, it is the fault of the teacher and no one else. This demonstrates that students are negatively affected by misbehaviors and they blame the teacher for those misbehaviors. This places more emphasis on teachers to monitor their behaviors because misbehaviors will be blamed on the teacher, and the teacher's credibility, competence, and teaching ability will be hurt because of this negative impression.

Banfield, Richmond, and McCroskey (2006) investigated teacher misbehavior and the effect on student affect and teacher credibility. Participants for this study were 288 undergraduate students enrolled in a communication course (Banfield et al., 2006). An experiment was conducted with four parallel conditions. Each participant was provided an alleged student's comments about a teacher. Three of the conditions addressed teacher misbehavior and one condition had no misbehaviors reported which was the control condition. After reading one of the descriptions, participants were asked to complete scales measuring their affect towards the teacher and their perceived teacher credibility (Banfield, et al. 2006). Results indicate that both teacher affect and teacher credibility were negatively affected by teacher misbehaviors (Banfield, et al. 2006). While all types of teacher misbehavior negatively affected the variables, the specific misbehaviors affected them to different degrees. Overall, teacher 
offensiveness had the greatest negative impact (Banfield, et al. 2006). This indicates that some misbehavior may be more harmful than others and may influence students’ perceptions differently.

Teacher control of misbehaviors. Wanzer and McCroskey (1998) examined teacher socio-communicative style and its influence on teacher misbehaviors. Teacher sociocommunicative style is “a communicator's skill in initiating, adapting, and responding to the communication of others” (Wanzer, \& McCroskey, 1998, p. 44). It is measured in two dimensions: assertiveness and responsiveness toward students (Anderson \& Martin, 1995).

Results from this study indicate that the more socio-communicative style teachers had, the less likely they were to misbehave. Students’ perceptions of teacher assertiveness and teacher responsiveness were negatively associated with teacher misbehavior (Wanzer, \& McCroskey, 1998). As teachers were seen to be assertive or responsive in communication, they were less likely to be perceived by students as misbehaving.

Immediacy has been defined as a perceived closeness (Mehrabian, 1969). Researchers examined the relationship between nonimmediacy and misbehavior (Thweatt, 1996; Thweatt \& McCroskey, 1997). The researchers utilized four conditions or scenarios involving perceived immediacy and perceived teacher misbehavior. The four scenarios were low immediacyappropriate, low immediacy-misbehavior, high immediacy-appropriate, and high immediacymisbehavior (Thweatt; 1996; Thweatt \& McCroskey, 1997). Participants in this study were 382 undergraduate students enrolled in communication classes. Results indicate that immediacy and misbehaviors of the teacher cannot be seen as independent. Students perceived low immediacy in itself as misbehavior (Thweatt 1996; Thweatt \& McCroskey, 1997). 
Thweatt and McCroskey (1998) investigated the impact of teacher immediacy and teacher misbehaviors on teacher credibility. Students enrolled in communication classes were the participants for this research. Study one had 197 participants and study two had 188 participants (Thweatt \& McCroskey, 1998). The second study was used to replicate the findings of the first study. Results indicate that when teacher misbehaviors were present, credibility on all three levels was affected negatively (Thweatt \& McCroskey). When misbehaviors are present, students will find the teacher to have less goodwill, less intelligence, and less character. An interaction effect was found between misbehaviors and immediacy on three levels of credibility. When immediacy was low, credibility was perceived to be low no matter how much misbehavior was present. Researchers found when immediacy was high and misbehaviors were present, credibility was perceived to be low (Thweatt \& McCroskey). Results indicate that if teachers utilize immediacy they are more likely to be perceived as credible if they do not misbehave.

Thweatt (1999) examined teacher misbehaviors, teacher credibility, and student affective learning and the mediating effect of immediacy and affinity seeking. The study exposed undergraduate students, enrolled in a communication studies course, to one of eight scenarios. Once exposed, students reported on their affective learning, teacher credibility, and made an evaluation of teacher behaviors (Thweatt, 1999). Results indicate that participants perceive teachers who are high in immediacy and affinity seeking as more positive. Once again results indicate that immediacy and teacher misbehaviors cannot be manipulated independently. Perceived credibility was higher for individuals who were perceived to not misbehave. Affective learning was negatively correlated with teacher misbehaviors (Thweatt). Overall results demonstrate that misbehaviors are negative toward the students' perceptions of the 
teacher, as well as to the course the teacher is teaching. This study also had some limitations that were previously addressed: quasi-experimental method, self-report, and an all college student population.

Paulsel and Terrazas (2002) also examined the influence of teacher immediacy, but examined immediacy in terms of behavior-alteration techniques and misbehavior on students’ perception of power. One hundred and sixty seven participants were in this study. They were composed of 62 males and 105 female college students (Paulsel \& Terrazas, 2002). Participants completed a questionnaire regarding their teachers’ perceived immediacy, teachers' use of behavioral alteration techniques, and their teachers' perceived misbehaviors. Results indicate that a positive correlation exists between antisocial behavioral alteration techniques and all three levels of misbehavior: indolence, incompetence, and offensiveness (Paulsel \& Terrazas). Teachers, who were perceived to use prosocial behavioral alteration techniques, utilize immediate behaviors and avoid misbehaviors. They were also perceived to use reward power or referent power (Paulsel \& Terrazas). Overall, teachers’ use of positive attributes will result in more positive types of power as well as more positive responses from students.

Toale (2001) examined the relationship between teacher clarity and teacher misbehaviors, along with variables of affective learning and teacher credibility. Teacher clarity is argued to be central to the encoding of information in long-term memory (Murray, 1991). When teachers are trying to pass on information or knowledge to their students, they need to be aware of the clarity of their message and how clearly they are sending that message. Another researcher found "that students perceive clear teachers as effective and that teacher clarity benefits student achievement” (Civikly, 1992). Participants in this study were 671 undergraduate students 
enrolled in communication classes (Toale, 2001). The participants, addressing their perceptions of teacher clarity, teacher misbehavior, teacher credibility, and their own affective learning, completed questionnaires. Results indicated that as teacher clarity increased the students affective learning and perceived teacher credibility also increased (Toale). When teacher misbehaviors were present, students' affective learning was reduced as well as perceived teacher credibility (Toale). Students perceived low clarity as misbehavior, and therefore results indicate no differences between low clarity and misbehaving teachers (Toale). Clarity is important for teachers, and when it is not present students perceived this as misbehavior.

\section{Cognitive Learning}

Most literature that has examined cognitive learning operationalized learning by asking students their final grades, how much they perceived themselves to be learning, or how much learning loss they had (Dolin, 1995). Learning, or to pass on some knowledge, is the reason why teachers instruct students. Dolin (1995) found that students who reported that their instructors participated in misbehaviors also reported that they felt their learning was also affected by such behavior. Students claim that they learn less from instructors who misbehave than from those instructors not participating in actions that would be perceived as misbehaving. Participants for this study were undergraduate students. The design of the study was a self-response to a questionnaire. Due to the fact that this self-response was a perception of the students' own learning, it did not measure direct cognitive learning. This is a draw back in the design of this study and will be addressed in the current study.

Researchers have compared perceived learning with actual learning by measuring both in students. Research was necessary to make sure that perceived learning was an accurate 
measurement. Chesebro and McCroskey (2000) examined the relationship between students’ reports of learning and their actual recall of information. Participants were 192 students from a larger university. Results indicate that perceived learning is related to actual learning. While this indicates that learning can be measured through students’ perceptions, teacher misbehaviors may or may not influence actual learning and still need to be addressed in the research. Other researchers examined cognitive learning in terms of outcome variables that can influence the learning.

Rodriguez, Plax, and Kearney (1996) examined the relationship between immediacy, affective learning, and cognitive learning. They proposed a model of motivational learning, indicating that affective and cognitive learning are connected. Participants in this study were 224 undergraduates in speech communication classes. Results indicated that when teachers used immediacy they increased the affective learning of students, which in turn should increase the cognitive learning of individuals.

Kelley and Gorham (1988) examined the effect immediacy has on cognitive recall. Through an experiment, researchers manipulated the level of immediacy that an instructor used and then measured the cognitive recall of students in the study. There were 100 undergraduate students in the study. There were four conditions: high physical immediacy with eye contact, high physical immediacy with no eye contact, low physical immediacy with eye contact, and low physical immediacy with no eye contact. Results demonstrate that when less immediacy cues were used, then cognitive recall decreased. Since misbehaviors are the opposite of immediacy behaviors, cognitive learning should decrease. 


\section{Motivation}

"Most psychologists and educators use motivation as a word to describe those processes that can (a) arouse and instigate behavior; (b) give direction and purpose to behavior; (c) continue to allow behavior to persist; and (d) lead to choosing or preferring a particular behavior” (Wlodkowski, 1984, p. 12). The goal of most instruction is learning; teachers are constantly trying to get students motivated in terms of learning. They want students to want to learn.

Teacher influence of motivation. Motivation has been the focus of many researchers and in particular, how teachers may influence motivation of students through positive and negative behaviors that they use in their teaching (i.e. Christensen, \& Menzel, 1998; Christophel, 1990; Deci, Vallerand, Pelletier, \& Ryan, 1991; Pogue, \& AhYun; Richmond, 1990). The first area that researchers have examined when considering motivation is how teacher behaviors are seen as motivators or demotivators.

Gorham and Christophel (1992) examined students’ responses when the students considered how teacher behaviors influenced their motivation level. There were 308 participants in this study. Participants were asked open-ended questions about what motivates or demotivates them in the classroom setting. Based on these questions 2404 responses were given. Students generated 1450 responses that were considered motivators and were coded into 20 categories. From these categories researchers determined which ones were the most frequently referenced. Interest and perceived relevance of material were referenced the most. This was followed by “teacher’s effectiveness and enthusiasm in lecturing; grade or credit motivation; teacher's use of student-centered behaviors; positive responses to the organization of the course and material; 
opportunity to participate and feedback from the instructor; personal achievement, teacher competence/knowledge” (Gorham, \& Christophel, 1992, p. 245). Other categories that emerged but were not as frequently referenced included “teacher’s sense of humor; general assessments of the teacher as a "nice guy”; satisfaction with assignments and grading; desire to please the teacher or someone else; and teacher's self disclosure and personal anecdotes” (Gorham, \& Christophel, 1992, p. 245).

Along with motivators, students also produced teacher behaviors that were perceived as demotivators. There were 926 student responses indicating a behavior was demotivating. The most referenced demotivator was a teacher who was boring or confused students. Others included "dissatisfaction with grading and assignments; negative responses to the organization of the course and material; the teacher's attitude toward students; dislike and perceived lack of relevance of the subject area; time of day, length of class, and personal factors; and the teacher's physical appearance” (Gorham, \& Christophel, 1992, p. 246). Results clearly indicate that teacher behaviors influence the perceived motivation or demotivation of students. Since misbehaviors are a negative behavior enacted by teachers, demotivation should result or a decrease in motivation should result.

The second area that researchers have focused on is how teachers use immediacy to influence student motivation. Christophel (1990) examined the relationship between teacher immediacy, student motivation, and learning. Two studies were conducted to determine the relationship between these variables. There were 562 undergraduate participants in study one. Results indicated that as a teacher used more verbal and nonverbal immediacy, students reported greater levels of motivation. This study also found that students' motivation predicted 
significant learning. As the motivation to learn increased, so did learning. Study two had 624 participants in group A who completed the motivation and immediacy scales, and 624 participants in group B who completed motivation and learning. Results indicated that student trait and state motivation was positively related to student learning with state motivation producing a higher predictiveness than trait. Overall, both studies found that motivation was positively influenced by teachers’ use of immediacy behaviors.

Frymier (1993) also examined teachers’ use of immediacy and how it would influence students' motivation throughout the semester. The goal of this research was to see if students would react differently when immediacy was utilized. Participants were composed of 178 undergraduate students who were enrolled in communication studies courses. Results supported previous research, indicating that when immediacy was used a positive relationship was found with motivation. Students' motivation at the beginning of the semester was found to be the largest predictor of motivation later in the semester. Students who had high motivation entering the classroom ended with high motivation at the end of the class no matter how immediate the instructor behaved. Differences were found in students who entered with low or moderate levels of motivation if they had an immediate teacher. These students reported higher levels of motivation at the end of the semester than at the beginning of the semester when the immediate teacher was present. (Frymier, 1993)

Christensen and Menzel (1998) researched the relationship between nonverbal and verbal immediacy and state motivation of students. The goal of their research was to establish a linear relationship between each kind of immediacy and motivation. Participants in this study were 115 undergraduate students. Results support previous findings of the positive relationship between 
student motivation and teacher immediacy. They also were able to assert that when immediacy was present it would influence motivation, establishing a linear model.

Carrell and Menzel (2001) addressed learning, motivation, and immediacy between different types of classrooms. Often in this day and age we have students who participate in distance learning that utilizes video or other methods to learn. Participants were composed of 169 undergraduate students from a variety of classes. There were three conditions in the study: a live classroom, a video classroom, and an audio with PowerPoint display classroom. Results indicate that the live classrooms reported more motivation, immediacy, and perceived learning.

Pogue and AhYun (2006) also examined immediacy and motivation but extended the research to address the instructors’ credibility. The researchers conducted an experiment in which teachers could have high or low immediacy and high or low credibility. Participants were given a written statement describing the teacher and then were asked to complete a set of scales about their motivation and affective learning. There were 586 participants in this study. Results indicated that when an instructor had high immediacy and high credibility students reported higher levels of motivation and affective learning. Participants also reported that their level of motivation and affective learning was the least when teachers had low immediacy and low credibility. Motivation is then influenced by teacher outcomes other than immediacy and this needs to be considered in research.

Houser (2006) also examined how many teacher variables influenced learning and motivation including immediacy, clarity, and affinity-seeking. Expectancy Violation theory was used to frame this research along with examining the difference between traditional and nontraditional students. Participants were composed of 169 traditional students and 158 
nontraditional undergraduate students. Results indicated that, in general, nontraditional students reported more state motivation and cognitive learning. Motivation was found to highly influence how students approach a class, and since nontraditional students are more motivated they are more likely to emphasize their learning in the class. When teachers' clarity violated the expectations of students negatively, it also negatively influenced students’ motivation and cognitive learning. Misbehaviors often increase the perceived distance between the teacher and student. This would imply that when misbehaviors are present, immediacy would decrease as previously found (Thweatt, 1996; Thweatt \& McCroskey, 1997), and therefore decrease students’ motivation.

The third area that researchers have examined about motivation addressed when information is relevant to the student. General findings indicate that when information is relevant students become more motivated (Kerssen-Griep, 2001; Kerssen-Griep, Hess, \& Trees, 2003; Weber, 2002). Frymier and Shulman (1995) asked the question "What's in it for me?” This is central to how students often approach learning; if it is relevant content, then students can use this in the future or in their everyday lives. Participants in this study were composed of 470 undergraduate students. Results indicated that students who perceived content to be relevant exhibited more state motivation. Predictions were made indicating that motivation would be influenced by relevance and immediacy for a greater variance. This prediction was supported by results indicating that when combined, relevance and immediacy explained more of the variance than each by itself.

Kerssen-Griep (2001) examined how face-relevant instructional communication activities influenced students’ motivation to learn. Participants in this study were 45 graduate students and 
two university professors. Results indicated that when teachers communicated in a way that encouraged ownership of and investment in the class, it was face-addressing. This finding indicated that face-work can influence students, motivating individuals by giving them control or involvement in the classroom.

Other research also addressed face work related to student motivation to learning. Kerssen-Griep, Hess, and Trees (2003) addressed face work as teacher feedback about student work. Participants in this study were 423 students from public speaking classes. Results indicated that teachers' use of solidarity, approbation, and tact face work could predict students' intrinsic motivation to learn. This indicated that as students felt the feedback was relevant to them, they were more likely to be motivated in their learning.

Further research addressed how student interest was influenced by motivation. Weber (2003) examined interest and internal and external motivation. Internal motivation was conceptualized as intrinsic motivation and external motivation was identified as extrinsic. Participants in the study were 209 college students. Interest was found to be related to intrinsic motivation but not extrinsic motivation. Results also indicate that information that is considered meaningful to students increased internal motivation. Other motivation research examined behavioral alteration techniques. Richmond (1990) examined behavior alteration techniques and power, and how they are associated with student motivation. Participants in this study were composed of 366 undergraduate students. Results from this study indicated that the type of power influenced student motivation. Coercive power negatively influenced student motivation, while referent and expert power were positively associated with motivation. Some of the behavioral alteration techniques influenced motivation with authority-based and coercion-based 
negatively correlating with motivation. In the end, results indicated that a greater knowledge of how to influence students’ behaviors will lead to more motivation of students.

McCroskey, Richmond, and Bennett (2006) examined the relationship of motivation in the General Model of Instructional Communication. The researchers examined the primary variables of the General Model of Instructional Communication: nonverbal immediacy, clarity, assertiveness, and responsiveness. Participants in this study were 189 undergraduate students. Results indicate that when teachers use nonverbal immediacy, clarity, assertiveness, and responsiveness, students are more likely to be motivated to study. End-of-class motivation is specifically addressed and is more likely to be sustained in students if there are future opportunities to learn more about the subject.

Deci, Vallerand, Pelletier, and Ryan (1991) examined how student motivation can promote interest in learning, valuing education, and a confidence in their own abilities in education. Their research was framed with self-determination theory. Self-determination theory examines how people are motivated; when a behavior is self-determined, the process is motivated by choice, whereas when a behavior is controlled, the process is motivated by compliance or defiance (Deci, Vallerand, Pelletier, \& Ryan, 1991). Results were compiled applying self-determination theory to previous research. Findings indicated that when selfdetermination was present in terms of intrinsic motivation, positive outcomes in learning result. Students feel that they can make decisions that are driven by their own motivations as opposed to forcing a particular extrinsic motivation on them. Academic Self-efficacy.

A students’ academic self-efficacy is very important to the learning process. Many 
researchers have examined academic self-efficacy. The following section will address what previous research has found about students’ academic self-efficacy.

Self-efficacy clarification. Lent, Brown, and Gore (1997) examined the relationship between self-efficacy and self-concept. Previous research according to Lent, et al. (1997) considered these two variables as possibly measuring the same concepts. Academic self-concept has been seen as “attitudes, feelings, and perceptions relative to one's intellectual or academic skill” (Lent, Brown, \& Gore, 1997, p. 308). Self-efficacy, on the other hand, has been defined as “personal judgments about one’s ability to perform a given task or course of action” (Lent, et al. p. 307). The purpose of this research then was to distinguish the two concepts and establish that they were indeed unique variables. Participants in this study were 205 psychological students composed of 54 males and 151 females. Results support the findings that self-efficacy and selfconcept are indeed two different variables or constructs. They are not interchangeable constructs. Pajares (1995) examined the concept of self-regulation and motivation in academic settings. The author applied the theory of self-efficacy to these concepts of self-regulation and motivation. The author applies this theory of self-efficacy to studies that have already been conducted. The results indicate that when self-efficacy is included in statistical models, selfefficacy is a strong predictor of academic performance. Results also indicate that self-efficacy may be a mediator between academic performance and other determinants (Pajares, 1995).

Hierarchical nature of self-efficacy. Kim and Park (2000) examined how different types of self-efficacy play a role in regards to academic performance and to see if a hierarchy was present for self-efficacy. Participants were from a typical Korean high school and were composed of 361 males and 400 females. Individuals completed a questionnaire composed of 
Korean general self-efficacy scale, academic self-efficacy scales, and subject-specific selfefficacy.

Results indicate that subject-specific self-efficacy was the best predictor of specific subject achievement. While this was the best predictor, self-efficacy expectation in one subject also predicted the expectation in other subject areas (Kim \& Park, 2000). This differs from other studies that say that efficacy is more predictable of only the specific subject and nothing else. This study supports the idea that other types of efficacy can be just as strong, predictable, or valid (Kim \& Park, 2000).

Bong (1997) examined the concept of academic self-efficacy and its hierarchical relations. Participants were composed of 588 students from four high schools in Los Angeles County, California. Evidence supports the idea that subject specific efficacy can predict the outcome of the subject addressed by the efficacy. Results also indicate that while this is a strong predictor, general self-efficacy can be used to predict academic outcomes across many subjects. This supports research that a students' efficacy can be measured that addresses general efficacy rather than having to rely on subject-specific efficacy. In this study general academic efficacy will be utilized so that understanding of how misbehaviors affect students can be generalized to other subject areas rather than one area of content.

Self-efficacy and learning outcomes. Maier and Curtin (2005) examined how selfefficacy helps journalism students develop research method skills. The authors divided their findings into two studies. The first study addressed information such as demographics, which included the participants’ math education, a series of questions regarding the participants’ perceived ability of math, and their attitude toward learning research methods. Forty-one 
journalism students completed the first study. The second study was conducted one year later after the research methods course had been revamped utilizing the theory of self-efficacy, making it clear to individuals that the class was applicable to their real life. The researchers were participant observers in weekly meetings of the class. The points of the meetings were to help with self-efficacy of the students’ learning of research methods. Based on the notes taken during the meetings, the authors examined the participants’ feelings about math as well as their attitude towards learning research methods. They also examined the math exams that the students were given to understand their actual learning. These meetings outside of class time varied in participants because they were optional.

Results indicate that the students who were able to utilize the out of class meetings experienced improved math skills, supporting the theory of self-efficacy. By giving individuals another area or arena to control their learning, they were learning better. The authors also propose strategies that increase the self-efficacy in research method teaching: guided mastery, peer modeling, verbal modeling, repeating exercises, less is more, avoid comparative modeling, establishing relevance, and keeping the faith (Maier, \& Curtain, 2005).

Chemers, Hu, and Garcia (2001) examined how self-efficacy influences first-year college student performance and adjustment. Participants in this study completed questionnaires regarding their social adjustment to their first-year experience along with their self-efficacy about the experience. The study was a longitudinal study that examined students throughout their first year. There were 373 students in the first round of the study and 256 responded a second time at the end of the study. Results indicate that self-efficacy showed a positive relationship with academic performance and personal adjustment (Chemers, Hu, \& Garcia, 2001). In other 
words, if students reported higher self-efficacy they were more likely to have better grades and better academic outcomes at the end of the study.

Christie and Segrin (1998) examined how self-efficacy and gender influence performance of social and nonsocial tasks. The authors divided participants into two groups: social task group and nonsocial task group. The social task group completed a task that was a speech and the nonsocial task group completed a math test. In the first group, social task group, 183 undergraduate students participated. There were 123 females and 60 males. In the second group, nonsocial task group, 75 undergraduate students participated. There were 45 females and 30 males in this group (Christie \& Segrin, 1998).

Both the social task group and the nonsocial task group completed the personality assessment questionnaire (Spence \& Helmreich, 1978), parental academic history, self-rated competence scale (Spitzberg \& Cupach, 1989), task-specific self-efficacy, and task performance. The study found that self-efficacy does influence task performance. Gender was found to influence the self-efficacy of which tasks to approach (Christie \& Segrin, 1998). This supports the idea that self-efficacy will influence the performance in academic areas.

Abu-Jaber and Qutami (1998) found that students’ self-efficacy of computers was influenced by cognitive thinking style. There were 164 undergraduate participants in an introductory computer course in the study. The participants completed the self-efficacy scale of computer skills (Murphy, Coover, \& Owens, 1989) and the cognitive thinking style scale. Results indicated that students who used abstract cognitive thinking style in regards to computers also reported more self-efficacy in regards to their computer skills (Abu-Jaber \& Nayfeh, 1998). This reiterates the idea that self-efficacy will influence how individuals learn and how they think 
about topics.

Self-efficacy on teachers. Wiltse (2002) examined how instructors’ comments influenced college students. Writing efficacy was addressed in this study among many other variables. The participants were composed of 181 undergraduate students with 104 female and 77 male participants. Participants completed surveys involving grade point average, writing self-efficacy, writing apprehension, and feedback. Results indicate that writing self-efficacy was negatively related to writing apprehension. This means that people who felt they were in control of their writing would also report less apprehension in writing activities. Self-efficacy was also related to writing outcomes expectations. These were found to be correlated; if a person had self-efficacy they also had more positive outcome expectations for their writing (Wiltse, 2002).

Mottet, Beebe, Raffeld, and Medlock (2004) examined the teachers’ self-efficacy and job satisfaction in the classroom. They examined how teachers were influenced by their students' verbal or nonverbal responsiveness. The study was composed of 112 instructors; 10 were full professors, 21 were associate professors, 26 were assistant professors, 26 were instructors or lecturers, 40 were graduate teaching assistants, and three did not indicate their academic rank. Teachers were then shown one of four movie conditions: high nonverbal, low nonverbal, high verbal, or low verbal. Self-efficacy of the teacher as well as job satisfaction were measured using a five-item scale. Results indicated that students' nonverbal responsiveness had a greater impact on teachers' self-efficacy and job satisfaction than verbal responsiveness. Both verbal and nonverbal responsiveness affected job satisfaction more than self-efficacy of the students (Mottet, Beebe, Raffeld, \& Medlock, 2004). 
Curiosity and exploration

Kreitler, Zigler, and Kreitler (1984) explored the relationship between the factors of curiosity and probability-learning strategies that individuals use. The factors of curiosity are manipulatory curiosity, conceptual curiosity, and curiosity about the complex or ambiguous. Participants were 75 first graders composed of 38 boys and 37 girls (Kreitler, Zigler, \& Kreitler, 1984). Each participant was involved in three 30-minute sessions, which measured their curiosity and learning strategies (Kreitler, Zigler, \& Kreitler). Results indicate that curiosity is important in children's performance on probability-learning tasks. The strategies of maximizing and frequency of preservation patterns were negatively related to all types of curiosity. Variability as a strategy was positively related to all three types of curiosity. Frequencies of systematic patterns were related positively to curiosity about the complex or ambiguous and negatively related to manipulatory curiosity (Kreitler, Zigler, \& Kreitler). This demonstrates that children's learning strategies are affected by their curiosity. If they are more curious they will choose strategies that will allow them to be curious rather than strategies that would not allow their curiosity to work. Misbehaving teachers may not allow students to use strategies that would develop and spark their curiosity.

Boykin and Harackiewicz (1981) examined the relationship between epistemic curiosity, incidental recognition, and the degree of uncertainty. The participants in this study were 64 high school seniors or college undergraduates taking summer courses at Cornell University (Boykin \& Harackiewicz, 1981). Participants were given 32 word frequency problems. They were instructed to determine out of four words what the most commonly used word was. There were four levels of uncertainty in the problems, determined by the varying degree of difference between the 
standard frequency index of the target word and the standard frequency index of the other three words. Once the participants had identified their answer, they also reported how confident they were with their answer and whether they wanted to learn what the right answer was. Results indicate that epistemic curiosity and recognition had increasing relationships to the degree of uncertainty and expressed curiosity (Boykin \& Harackiewicz). These results imply that the need to reduce uncertainty will create a need to understand or know information and will lead to curiosity behaviors.

Minuchin (1971) explored the idea of curiosity in the case of preschool disadvantaged children. Participants were 18, four-year-old African-American children in a Head Start program. The researcher first wanted to assess the exploratory behaviors of individuals, and then compare their exploration against other variables. Children who demonstrated more exploratory behaviors were found to "differentiate their self-image, have the strongest expectations of support, coherence, facilitation from the environment, and greater conceptual mastery” (Minuchin, 1971, p 948). This data supports the idea that curiosity is affected by outside sources such as their living situation, as well as curiosity affects the expectations on how others should behave, and that a level of support should be present (Minuchin, 1971). This helps demonstrate that if the teacher is misbehaving and not supporting students, curiosity will not get the support it needs to develop and will lessen for the student in question.

Lowry and Johnson (1980) examined how controversy affects curiosity, achievement, and attitudes. The authors felt that conflict would positively affect curiosity, achievement, and attitudes because of the inconsistency within conceptual conflict (Lowery \& Johnson). This motivates individuals to search for information that will allow the conflict to be resolved, so an 
increase in curiosity, achievement, and attitudes will be present.

Participants for this study were 80 fifth and sixth grade students. There were 40 fifth grade students: 20 boys and 20 girls, and there were 40 sixth grade students: 20 boys and 20 girls (Lowery \& Johnson, 1981). There were two conditions present in the study and each participant was assigned to a group. In condition one the participants were involved in a group discussion that included controversy among members. In condition two participants were involved in a group discussion that did not involve controversy (Lowery \& Johnson). They worked in these groups for two full weeks, or ten days, meeting an hour a day to complete a project assigned by the researchers. Observations were used at the time to examine how group interactions went; participants also completed a questionnaire that addressed information accurately learned, attitudes toward subject, controversy, peers, and amount of information-seeking behavior (Lowery \& Johnson).

Results indicate that individuals in the controversial condition were more likely to seek information; this curiosity led to more reading and viewing of material to seek out more information (Lowery \& Johnson, 1981). These participants were able to achieve more because they were seeking more information and learning more about the topic, so the project was more completely researched. Participants also had a more positive attitude toward the project because they all felt they had contributed to the project a great deal (Lowery \& Johnson). This study demonstrates when positive and controlled conflict is present, individuals can learn better. When a teacher misbehaves, the conflict is often negative and does not foster a curiosity or motive to learn more.

Sax and Stollak (1971) examined how curiosity was affected by the parent-child 
relationship. The authors particularly examined the effect of mothers on their children.

Researchers felt that because children are influenced in many ways by parents, these parents will also influence the children’s curiosity. Participants were compiled from a list of male students that teachers rated into four groups: high-curiosity-high prosocial group, low-curiosity group, high-aggressive group, and high-neurotic group. Forty parents agreed to allow their children to participate in the study (Saxe \& Stollak, 1971).

Each mother and her son were brought into a playroom to be observed in their interaction with the provided stimuli (toys and activities). They were observed through a one-way mirror by trained observers. Every 20 seconds an observer would categorize the child's behavior. Results indicated that if either the mother or the son demonstrated curiosity behaviors, the other was more likely to reciprocate that curiosity in return (Saxe \& Stollak, 1971). This demonstrates a reciprocal relationship of curiosity between parent and child. These reciprocal relationships may also be present in teacher-student relationships. If the teacher expresses curiosity for what the student is doing, he/she may influence the students’ curiosity. Teacher misbehaviors may once again negatively affect curiosity because of the lack of curiosity demonstrated by a teacher who misbehaves.

Henderson and Moore (1980) also examined the relationship between children’s responses to novelty items compared with their level of curiosity and adult behavior. Participants were 48 preschool children ranging from three and a half to five years of age. They were randomly assigned to either one of three adult-behavior conditions where novel toys were present or a control condition where only conventional toys were present. The adult conditions were demonstration, responsive, and unresponsive conditions. 
Results indicated that the adult would not affect a child's curiosity if that child was considered to have high-curiosity. This means if children were curious, they would be curious and want to discover new things on their own. Results also demonstrated that low curious children were less likely to be curious no matter the adult condition they were in. This leads researchers, parents, and teachers to recognize that self motivation will not always drive curiosity; to keep some children engaged in play or activities, adults must work harder and find ways to increase creativity. Because we know that individuals have different levels of curiosity that can be reached through different means, teachers who misbehave can be shutting down curiosity or not activating curiosity when it is needed. 


\section{Chapter 3- Methodology}

\section{Participants}

Participants in this study were current, traditional, undergraduate college students. The number of individuals enrolled in this research was 79 . There were 47 males and 32 female participants in this study. The majority of them were freshman with 67 indicating that level of education, five were sophomores, two were juniors, three reported being a senior, and two did not report. Ages ranged from 18 to 21. Fifty participants reported being 18 years of age; 21 were 19; four were 20; and four were 21. They were recruited from introductory communication studies classes at a large university. Participants volunteered to participate in one of four teaching conditions. A convenience sample was used as students in existing classes were asked to volunteer for research outside of their classroom. The institutional review board at the university approved the research before participants were approached.

Research Problem: Are student responses of cognitive learning, motivation, academic selfefficacy, and curiosity influenced by teacher misbehaviors?

$\mathrm{H} 1_{\mathrm{a}}$ : Students' cognitive learning will be negatively influenced by teacher misbehaviors. $\mathrm{H} 1_{\mathrm{b}}$ : Students’ motivation will be negatively influenced by teacher misbehaviors. H1 $1_{c}$ : Students’ academic self-efficacy will be negatively influenced by teacher misbehaviors.

$\mathrm{H} 1_{\mathrm{d}}$ : Students' curiosity will be negatively influenced by teacher misbehaviors. H2: Offensive teachers will have the most negative outcome on students followed by incompetent, and indolent. 
Procedures

In all conditions participants completed a pretest to test their knowledge of Computer Mediated Communication one week before they participated in the instructional manipulation. Along with testing their cognitive knowledge on the subject of Computer Mediated Communication, students were asked if they have had a class that discussed CMC. A pretest was necessary to make sure that the manipulation for the experiment was working. This was to ensure that the groups are equal.

During the teaching activity students were told they would "hear a lecture on Computer Mediated Communication” and were instructed to pay attention like they would in any class. A lecture was scripted which discussed Computer Mediated Communication. This lecture was chosen because the topic was not widely discussed in communication studies classes and addresses a communication studies topic. The lecture lasted approximately 15-20 minutes. Although the content was relevant to what the students were learning, they would have had a greater likelihood of not being exposed to this material because it was not as prevalent as other communication topics. Four versions of the lecture were scripted; three were manipulated by using specific misbehaviors to address each type: indolence, incompetence, and offensiveness (see appendix).

To assure that Computer Mediated Communication had not been taught to participants, they were asked if they had taken a class or had any units addressing Computer Mediated Communication. Only one participant reported CMC as the main topic of their class and eight participants reported units being covered regarding CMC in class. Six of the participants reported only one unit, 1 reported three units, and 1 reported 4 units being covered. These students were 
included in the study results. This indicates that while this is a general topic few participants had formal education addressing it.

The instructor that was used conducted all four conditions. The individual used as instructor was unknown to the students to alleviate any potential bias of being previously exposed to that instructor. The instructor was trained by the researcher to make sure he/she enacted the behaviors. To assure the instructor was manipulating his/her behaviors correctly, he/she was videotaped. The video was only of the instructor, focusing on the instructor's behavioral differences in each condition. This allowed the researcher to interpret the outcomes as a result of the different behaviors enacted by the instructor. After the teaching activity, students completed a post-test that tested the knowledge conveyed, i.e., their cognitive learning. Once they had completed the post-test, students also completed a questionnaire regarding their motivation, academic self-efficacy, and curiosity. Along with these questions participants also completed demographic information.

\section{Design}

The design for this study was a quasi-experimental design with limitations. Pretestposttest was used to create a stronger study. There were four conditions in this study. A statistical power analysis indicated that to reach statistical significance at the $\mathrm{p}<0.05$ level a sample size of 40 participants is needed. Students voluntarily assigned themselves to one of the conditions, which was a limitation to the quasi-experimental design. While they chose the most convenient time for them the participants were unaware of the actual condition content. There was one external validity issue that emerged with this design: pretest-interaction. To understand how much an individual is learning we must first understand what they already know. That is why a 
pretest was necessary for this study; the pretest, however, may increase the students' awareness that they should learn or remember certain things from the lesson, creating an external validity problem. This was controlled by having the pretest given to participants a week before the actual exposure to the condition. In a normal teaching situation students may also clue in on what is important and pay more attention based on how the teacher teaches.

\section{Teaching Conditions}

Each condition involved a teaching activity that lasted approximately 15-20 minutes. The teacher instructed students about Computer Mediated Communication. In each condition the topic was the same as well as the instruction, with the only difference being the misbehaviors enacted. First, Condition A, there were no misbehaviors present. Second, Condition B, the teacher demonstrated misbehaviors that would be considered incompetent. Specifically in this condition the instructor used no variation in vocals and showed little enthusiasm for being there. Third, Condition C, the teacher performed misbehaviors that were considered indolent. Specifically the teacher showed up late and stated that he/she just "lost track of time". Throughout the lecture the teacher acted disorganized, changing the direction of the lecture as if he/she forgot to add something. Finally, Condition D, the teacher demonstrated misbehaviors that would be considered offensive. The teacher enacted this behavior through the specific use of sarcasm in general to students. During each condition only a few misbehaviors were manipulated to try to achieve a more realistic classroom setting. Previous research has indicated that teachers do not often enact teacher misbehaviors, and when they do, not every single behavior would be considered misbehavior (Dolin, 1995). The teacher was not constantly misbehaving to make the misbehaviors more realistic. 
A manipulation check was conducted to make sure each condition truly addressed each type of teacher misbehavior. Participants in the manipulation check were 30 students in an introductory communication class. Of the participants, 83 percent indicated the correct condition after being exposed to the condition script. The five that indicated the wrong condition had been exposed to a misbehaving teacher but chose the wrong type of misbehavior; none thought that the teacher was a good teacher. This indicates that all participants recognized that the teacher was either misbehaving or behaving, but five of the participants were confused about what type of misbehavior was going on.

Measures

The first measure addresses students’ cognitive learning of the content. This test was composed of 20 multiple choice questions regarding the content of the lecture $(M=15.16, S D=$ 2.35). On the test were questions that made students apply the knowledge they had just learned to concepts. Five individuals were asked to examine the test along with the lecture notes to see if the assessment was valid and fair.

Motivation was measured using the Motivation Scale that Richmond (1990) developed. This is a five item bipolar measure, which extended Beatty, Forst, and Stewart's (1986) threeitem scale. The scale was expanded to increase the reliability of the scale. Items included in this measure were motivated-unmotivated, excited-bored, uninterested-interested, involveduninvolved, and dreading it-looking forward to it. Reliability for this instrument has been reported at .94 to .95 (Frymier, 1993a; Frymier \& Thompson, 1992; Richmond, 1990). For this study a reliability for this instrument was $.89(M=21.21, S D=7.42)$. Test retest reliabilities were reported at .80 (Frymier, 1993a). These reliabilities help establish that the State Motivation 
Scale is consistent in its measurement. Direct research has not addressed validity of this scale; however, many researchers have used this measure and potentially established construct validity (Frymier, 1993a; Frymier \& Thompson, 1992; Richmond, 1990). While not directly addressed, researchers have correlated participants' scores with higher and lower scores on some other relevant variables such as behavior alteration techniques (Richmond, 1990), immediacy (Frymier, 1993a, Frymier, 1993b), affinity-seeking behaviors, teacher character, and teacher competence (Frymier \& Thompson, 1992).

Self-efficacy was measured using the Learner Empowerment Scale (Weber, Martin \& Cayanus, 2005). This scale measures student interest and is a shortened scale from an earlier version (Frymier, Shulman, \& Houser, 1996). It is composed of three subscales: meaningfulness, impact, and feelings of competence. This is an 18 item report with responses ranging from (1) completely disagree to (7) completely agree. One of the subscales was used to operationalize state academic self-efficacy, competence. This created a six-item scale. Competence measures participants' own evaluation of their abilities in the classroom. Reliabilities for each factor have been reported as .91 for competence (Weber, Martin, \& Cayanus, 2005). For this study a reliability of .82 was found $(M=25.14, S D=7.29)$. Weber, Martin, and Cayanus (2005) established construct and concurrent validity in their study of the learning empowerment scale. By correlating the scale with motivation and then comparing the same correlation to the longer version of the scale, the authors were able to establish concurrent and construct validity. Construct validity was also established by examining the different relationships each factor had with motives (Weber, et al. 2005).

The participants' curiosity was measured using the Melbourne Curiosity Inventory State 
form (Naylor, 1981). This scale was designed to measure participants’ curiosity at the particular time of collection, not their overall general curiosity. Twenty items compose the scale with responses ranging from (1) almost never to (4) almost always. Reliability of this scale has been reported as .94 (Naylor, 1981). Reliability of alpha for this scale was found to be $.82(M=47.85$, $S D=12.34)$. Validity of the scale has been established by the many studies that have used the scale along with the correlations of the Melbourne Curiosity Inventory to other scales of curiosity (Boyle, 1983; Naylor, 1981; Reio, Petrosko, Wiswell, \& Thongsukmag, 2006). 


\section{Chapter 4- Results}

The current study examined how teacher misbehaviors could influence students in a mock classroom setting. Negative outcomes were predicted when teacher misbehaviors were present. Results were analyzed through two statistical analyses: ANCOVA and ANOVA. Research Problem: Are students' responses of cognitive learning, motivation, academic selfefficacy, and curiosity influenced by teacher misbehaviors? Based on this research problem the following hypotheses were proposed.

The first hypothesis predicted that students’ cognitive learning would be negatively influenced by teacher misbehaviors. The null hypothesis would be that students' cognitive learning will not be influenced by teacher misbehavior. A One-Way ANCOVA was used to analyze this relationship using pretest scores as the covariant, thus controlling for any differences in previous knowledge. An ANCOVA has two basic assumptions: the relationship is linear and homogeneity of regression. The first assumption is that the relationship between the cognitive tests is linear. The second assumption is that while it is a linear relationship it is also assumed to be parallel (Hinkle, Wiersma, \& Jurs, 2005). If the level of statistical significance $(\mathrm{p}<.05)$ was reached, the null hypothesis was rejected. The ANCOVA was not significant: F $(3,75)=1.16$, p $=.332$. Results indicate that no significant difference appeared between any of the groups based on cognitive learning. This means that the researcher failed to reject the null hypothesis. The covariate results indicate that the pretest and the cognitive test were significantly related to each other: $\mathrm{F}(3,72)=3.74, \mathrm{p}=.015$. This controls for previous knowledge of Computer Mediated Communication. 
Table 1

Mean and Standard Deviations for Cognitive Learning

\begin{tabular}{lcc}
\hline Teaching Teacher Condition & $\mathrm{M}$ & $\mathrm{SD}$ \\
\hline Offensive Teacher Condition & 14.20 & 2.03 \\
Incompetent Teacher Condition & 15.34 & 3.24 \\
Indolent Teacher Condition & 14.91 & 1.87 \\
Good Teacher Condition & 15.51 & 1.99 \\
\hline
\end{tabular}

The second hypothesis predicted that students’ motivation would be negatively influenced by teacher misbehaviors. The null hypothesis would be that students' motivation will not be influenced by teacher misbehavior. A One-Way ANOVA was used to analyze this relationship. An ANOVA is used to compare the differences among groups, in this case the different conditions, to see if there are any differences. There are three assumptions for running this statistical test: independence, normality, and homogeneity of variances. Each case must be independent from the other, meaning that the specific misbehaviors can only be present in one condition. This creates independence in all four conditions. The second assumption is normality. This assumes that each group has a normal distribution of results. The third assumption is homogeneity of variances. This means that the variance of data from each condition will be the same (Hinkle, Wiersma, \& Jurs, 2003). If the level of statistical significance $(\mathrm{p}<.05)$ was reached the null hypothesis was rejected. The ANOVA result was: $F(3,74)=13.98, p=.362$. Based on results there was no significant difference in motivation across the conditions. 
Table 2

Mean and Standard Deviations for Motivation

\begin{tabular}{lcc}
\hline Teaching Teacher Condition & $\mathrm{M}$ & $\mathrm{SD}$ \\
\hline Offensive Teacher Condition & 19.06 & 8.17 \\
Incompetent Teacher Condition & 18.40 & 4.64 \\
Indolent Teacher Condition & 18.62 & 6.42 \\
Good Teacher Condition & 16.35 & 4.59 \\
\hline
\end{tabular}

The third hypothesis predicted that students’ academic self-efficacy would be negatively influenced by teacher misbehaviors. The null hypothesis would be that students' academic selfefficacy will not be influenced by teacher misbehavior. A One-Way ANOVA was used to analyze this relationship. An ANOVA is used to compare the differences among groups, in this case the different conditions, to see if there are any differences in the scores of academic selfefficacy. If the level of statistical significance $(\mathrm{p}<.05)$ was reached the null hypothesis was rejected. A significant relationship was established between the independent variable teaching condition and the dependent variable academic self-efficacy. The results for the ANOVA indicated a significant self-efficacy difference among the groups. The ANOVA was significant: $F(3,75)=6.19, p=.001$. The strength of the relationship accounted for $20 \%$ of the variance of the dependent variable.

Post hoc tests were conducted using a Bonferroni test to evaluate which group means differ from which other group. There was a significant difference in means between the group that was exposed to good teaching and the group exposed to indolent teaching. The group that 
was exposed to indolent teaching scored lower on the academic self-efficacy scale. There was a significant difference between offensive and indolent teaching, with participants reporting a higher self-efficacy with an offensive teacher than an indolent teacher. No significant difference was found between good teaching and offensive or incompetent teaching.

Table 3

Mean and Standard Deviations for Academic Self-Efficacy

\begin{tabular}{lcc}
\hline Teaching Teacher Condition & $\mathrm{M}$ & $\mathrm{SD}$ \\
\hline Offensive Teacher Condition & 28.59 & 7.43 \\
Incompetent Teacher Condition & 25.05 & 5.36 \\
Indolent Teacher Condition & 20.19 & 8.36 \\
Good Teacher Condition & 27.38 & 4.97 \\
\hline
\end{tabular}

The fourth hypothesis predicted that students’ curiosity would be negatively influenced by teacher misbehaviors. The null hypothesis would be that students' curiosity will not be influenced by teacher misbehavior. A One-Way ANOVA was used to analyze this relationship. An ANOVA is used to compare the differences among groups, in this case the different conditions, to see if there are any differences in the reported curiosity. If the level of statistical significance $(\mathrm{p}<.05)$ was reached the null hypothesis was rejected. A significant difference was found among the groups regarding curiosity. The ANOVA was significant: $F(3,75)=3.59$, $p$ $=.018$. The strength of the relationship accounted for $13 \%$ of the variance of the dependent variable.

Post hoc tests were conducted using a Bonferroni test to evaluate which group means 
differ from which other group. There was a significant difference in means between the group that was exposed to good teaching and indolent teaching. The group that was exposed to an indolent teacher scored significantly lower on the curiosity scale. No significant difference was found between good teaching and offensive or incompetent teaching.

Table 4

Mean and Standard Deviations for Curiosity

\begin{tabular}{lcc}
\hline Teaching Teacher Condition & $\mathrm{M}$ & $\mathrm{SD}$ \\
\hline Offensive Teacher Condition & 50.88 & 14.14 \\
Incompetent Teacher Condition & 49.10 & 9.48 \\
Indolent Teacher Condition & 40.76 & 13.72 \\
Good Teacher Condition & 51.29 & 9.27 \\
\hline
\end{tabular}

The fifth hypothesis predicted that offensive teaching would have the lowest cognitive scores for students followed by incompetent, and indolent teaching. The null hypothesis would be that teacher offensiveness would not have the lowest cognitive scores. For hypothesis two a One-Way ANCOVA was used to analyze the data. If the level of statistical significance $(\mathrm{p}<.05)$ was reached the null hypothesis was rejected. The level of significance was not reached and so the researcher failed to reject the null hypothesis. The results of an ANCOVA were: F $(3,75)=$ 1.16, $\mathrm{p}=.332$. While these differences did not reach statistical significance, the order of the means reflected the prediction of the offensive condition scoring lower than the rest of the conditions (see table 1). 


\section{Chapter 5- Discussion}

While the results that were found were not expected, they still have value. Only two of the hypotheses were supported by data. Hypothesis $1 \mathrm{C}$ that addresses academic self-efficacy was found to have a significant difference between good teachers, offensive teachers and indolent teachers. This is logical with participants scoring higher in self-efficacy with good teachers and offensive teachers and lower with indolent teachers. Based on the manipulation, the good teacher and offensive teacher asked for examples, encouraged participation of students, and sought feedback from students, thus engaging the students during the lecture. This can lead students to feel like they have control of their own learning and more say in the teaching situation. These results indicate that for students to have greater academic self-efficacy teachers should involve their students in the educational process by asking for examples and their own thoughts on the topic. Another interesting result is that even if the teacher was misbehaving, in the case of offensive teachers, students can still have higher academic self-efficacy. This indicates that while a teacher can misbehave to a certain extent, if students are given the opportunity to give feedback or participate, they will still maintain their academic self-efficacy.

The second hypothesis that was found to be significant was Hypothesis 1D. The data indicated that there was a significant difference between the conditions of good teaching and indolent teaching. Students exposed to good teachers reported higher scores of curiosity. Those participants who were exposed to the indolent teacher had significantly lower curiosity scores. Indolent teachers are found to lack caring towards students. This lack of caring can result in students disconnecting from the material being covered which results in a reduction of curiosity. This finding indicates that if a teacher does not indicate that they care about and want the student 
to engage in the material being covered the student will not care about the material and show less curiosity about finding more about the topic.

Both of these results indicate that engagement may have been a better outcome variable to test. Research has found that the more a student is engaged the more likely they are to be a good learner (Skinner \& Belmont, 1993). Many researchers have described “engagement as a multidimensional phenomenon” (Handelsman, Briggs, Sullivan, \& Towler, 2005 p.185). One of the dimensions that has been identified was an interpersonal dimension. This dimension can be described as the interaction between teachers and students (Skinner \& Belmont, 1993). The interpersonal aspect of engagement may have been manipulated in the indolent condition but not in the other conditions. This created a situation where engagement became the manipulated behavior that was being measured for the indolent condition rather than the actual indolent behaviors. This could have resulted in a difference in the indolent condition from the other three conditions.

Based on the two significant results the indolent teacher condition was the only behavior that demonstrated a negative influence on the outcome variables. This may be explained because it was the most obvious misbehavior or engagement being manipulated. The teacher in the condition did not engage the participants in any way, not asking for feedback, reading from the scripted lecture, and not encouraging any type of interaction before or after the lecture. This could have been interpreted as indolence, not caring enough to try to engage or just not engaging. While the behaviors were obvious they were still realistic in nature. This obvious disconnect from the students could have resulted in this condition being very different from the other three conditions. The situation created a condition that was more extreme with misbehaviors easily 
identified by participants thus creating a weighted or more influential condition. If the teacher had not read from the script it may have been less obvious to the participants and the conditions may have appeared to be more equal and less different. The results then may have been altered.

One interesting anecdotal finding for this study is that the better the teaching condition was perceived the smaller the standard deviation for that condition when compared to conditions with more obvious misbehavior. This may indicate that when a teacher enacts less negative teaching behaviors the student's responses may be more predicable or stable. This stability or predictability may lead students to build expectations of the classroom setting. These expectations may allow them to feel more comfortable in the learning environment because they know how their teacher is going to behave.

After finding few differences between the conditions, results were analyzed using a nonparametric assessment: Kruskal-Wallis test. The nonparametric test was utilized post-hoc because the data that was collected would technically be ordinal data rather than interval or ratio data, which is assumed in parametric statistics such as ANOVA. While the ANOVA is an appropriate test the results may have been better explained by examining the median or rank of the score rather than the means of the participants' results. After conducting the post-hoc analysis the results were not different. Participants’ curiosity and academic self-efficacy were still significantly different. The other variables were still not significantly different.

While both hypotheses addressing academic self-efficacy and curiosity were found to be significant they only found a few conditions being significantly different from each other. This indicates a partial finding or an unexpected finding. Since academic self-efficacy and motivation were the only significant differences found between the conditions in this study, the other 
variables and concepts must be examined for why there was not a significant difference present. There are three main reasons for these results: the conditions, the cognitive test, and the participants themselves. The first reason that these results were found is due to the way the conditions were created. There are multiple ways the conditions were created that can explain the results: identifying three distinct conditions, realistic classroom setting, the number of misbehaviors represented, the length of exposure, and the familiarity/acceptance of the misbehavior.

One issue that could influence the outcome is trying to treat each type of misbehavior as a discrete and complete construct. Each condition may have overlapping features with other conditions, so the conditions may not have been measuring a specific type of misbehavior but a combination of all types. For instance when the indolent condition was manipulated, some individuals could interpret it as incompetent and that the teacher did not know how to teach. Others may interpret that same behavior as uncaring or indolent because the teacher did not care enough to connect with the student. The way the study was designed created four distinct conditions but the misbehaviors may not be as simple to manipulate so as to create experiences of distinct constructs. Potentially, combining the misbehavior conditions would show significant differences from the good teaching condition and explain how misbehaviors influence student outcomes in general. Further research may be needed to identify if the types of misbehaviors are distinct constructs that can be manipulated independently of each other.

The testing conditions were set up to represent a more realistic classroom setting from the professor to the number of students. The results would then reflect what could be happening in a true classroom setting rather than just an experimental setting. Then creating a valid measure of 
how teacher misbehaviors influence learning and student outcome variables in as close to a true classroom setting. By creating as normal a classroom setting the results should indicate how real teachers can also misbehave in a reasonable way without disrupting the potential learning in the class.

Not only did the realistic classroom setting influence the results, more importantly, the number of misbehaviors that existed in a class setting was manipulated. There were only a few misbehaviors represented in each of the conditions because previous research indicated that though teachers misbehave it is not on a regular basis (Dolin, 1995). It is possible that because the manipulation was more realistic and not intense, it did not negatively influence the learning or the learning outcomes of the students.

The misbehavior in this study also occurred in a single exposure rather than long-term multiple exposures further limiting the misbehavior influence. In most educational settings, the student is exposed to the teacher and the learning content through multiple events. In a true classroom setting there may be a threshold effect where the teachers reasonable misbehaviors build up to finally have a negative influence on learning and learning outcomes. Since the participants only had one teaching event the students may not have been negatively influenced by the teachers' behaviors. Therefore, their threshold for allowing misbehaviors to influence them was not activated.

This finding can help all teachers, and especially teachers who fear that they are misbehaving. Teachers who misbehave infrequently do not have to fear that one instance or one behavior will negatively affect the students as long as it is an infrequent and reasonable misbehavior. This is a logical outcome because many instructors and teachers would report that 
they enact behaviors that could be considered misbehaviors at some point in their teaching career (Banfield, 2008). Those same teachers who report that they misbehave can also be considered by their students to be good teachers. This may be because a teacher is judged by more than one instance or one lecture. They have a whole semester or more to build a rapport with their students; teachers can misbehave and the students can still learn and have a positive learning experience. While this can allow teachers to relax more in the classroom, they still must be aware of how their behaviors may have a negative impact on students and student learning. These results may also be explained by how the conditions were created.

All conditions were developed to represent a true teaching situation; therefore, a few misbehaviors were represented in each condition. Since only a few misbehaviors were picked to be manipulated, students may be familiar with and accepting of the misbehaviors as part of the normal classroom experience. The misbehaviors that were picked also reflected behaviors that would not do permanent or lasting damage to the participants. They may be perceived as weak misbehaviors but were used to avoid issues of long-term negative outcomes.

It was hypothesized that offensive teachers would be the worst out of all conditions; however, this was not supported. This finding can be because the main misbehavior that was manipulated for this condition was sarcasm. Sarcasm can be used as humor in our culture, and the students may not have found the teacher offensive but rather amusing. Other research has found that students often think, or can think of, sarcasm as humor (Banfield, 2008). Only the first statement in the offensive condition would be considered offensive and not sarcastic, the teacher stating, "I’m dumbing this down.” Because the rest of the misbehaviors were based on the use of sarcasm, the students may experience a recency effect and only remembered the sarcasm and not 
the rudeness. This condition may have had a greater impact through the use of direct or indirect insults to participants and not sarcasm. While sarcasm is potentially more acceptable insults are not. By utilizing insults students may have been more aware of the offensiveness of the teacher. The use of insults though should be represented an equal amount as sarcasm was in this study so that this would still create a more realistic classroom setting.

The other manipulated conditions: confusion, monotone, participation, and showing up late, while these are considered misbehaviors, the participants may experience them on a regular basis. Therefore, they may not be as negatively influenced by those particular behaviors. More extreme misbehaviors may be needed to find truly negative results but this can also lead to permanent negative outcomes for participants. As researchers we must decide if we need to subject participants to the potential permanent damage or not.

A second reason for the outcome of this study was how cognitive learning was measured. Cognitive learning was measured by using a multiple-choice test. While this streamlined the answers, it potentially created an easier testing format. By using a multiple-choice test, participants in the study could actually guess the right answer even if they did not have that knowledge. This potentially inflated the test scores of the participants. In the future, to test cognitive learning a different style of test should be utilized that avoids this type of inflation of scores.

The testing time could have also influenced the cognitive learning results. The test was given immediately after the lecture. This allowed students to use short-term memory or recall rather than long-term memory for the test. Since the results were based on this recall memory students may not have truly learned the content but because it was recently covered they could 
recall what had just occurred, scoring higher on the cognitive learning than they would have if the test had been given a week later. Future research should address a more long term memory rather than just recall or short-term memory.

Besides the format and time of the test, cognitive learning could have been influenced by the topic. The typical college student is much more astute in computer information than the rest of the population. While Computer Mediated Communication is not widely covered in a classroom situation, students still have common knowledge of different computer applications; therefore, the lecture may have had little to no influence on them. If the students felt they already knew the information they would have little motivation to pay attention to what the instructor was saying in the teaching condition. Therefore, the differences in the manipulation would not influence the students if they were not paying attention to begin with. While the researcher tried to control for previous knowledge of CMC, it was only done by looking at classroom exposure. The participants could have reported that they had little to no exposure to CMC even though they knew the content already from some place other than the classroom setting. This could change the results. In the future, another topic should be utilized that might not be influenced by previous knowledge.

A third explanation for these results was the participants themselves. There was little to no motivation to pay attention during the manipulation. The participants were instructed to pay attention like a normal class, but in a normal classroom setting they would have a grade that affects their grade point average in the end. This means in a real classroom setting there could be more consequences for not paying attention, thus creating extrinsic motivation for students. The extrinsic motivation, a grade, could cause students to care if the teacher misbehaves. In the 
current study the participants had no extrinsic motivation or negative outcome, such as a bad grade, to influence them to pay attention. Without this extrinsic motivation, participants may not make the effort that they normally would.

\section{Limitations}

For any study there are limitations. In this study there are five main limitations: the use of college students, the use of pretest, the fact that the assignment to conditions is not random, the small number of participants, and the use of only one teaching session. First, the use of college students limits the research in generalizability to other populations involved in education such as pre-kindergarten through grade 12, nontraditional, and continuing education students. This is a starting point for this teacher misbehavior research but should not be the only students addressed. Future research should examine other educational populations to determine if teacher misbehaviors are the same or if they influence different students differently.

Second, a pretest can be a limitation because there is a potential for weighted consequences. Participants were exposed to the cognitive test a week before they heard the lecture. This may have led the participant to be more aware of information and pay attention differently during the lecture condition. This limitation was addressed by giving the test a week in advance to alleviate some of the ability for participants to remember the items on a short term.

Third, another limitation is that random assignment to conditions was not used. Random assignment would have made the study stronger, but because of the constraints of having only one instructor, conditions could only be performed one at a time. To ensure participation would occur, participants self-identified a time that they could attend. This makes the assignment not random. Future testing should include random assignment to conditions by having multiple 
sessions at the same time, which would allow for random assignment to each condition.

The fourth limitation is the small number of participants. While this can cause the results to not be as powerful, the small number was chosen to make the teaching conditions as realistic as possible. Reality was found to be more important than the number of participants so that results could have stronger face validity for a teaching situation. Future research should use multiple sessions of the same condition to increase the participant numbers potentially increasing the strength of the results or the generalizability of the results.

The fifth and final limitation to this study is that it only used one teaching session. Most instruction happens with more than one interaction. Future research should utilize a more ethnographic method and look at how time may be a factor. If a teacher is misbehaving infrequently but over a four-month period, this may build up a negative impression for the students. After a time, this build up could harm students' learning, motivation, self-efficacy, and curiosity.

Future research and implications. Future research should address some of the limitations pointed out by this study, such as the methods issues just described. Different populations outside of the college student demographic need to be addressed. There can be differences in other types of student's perceptions of misbehavior such as at the high school or middle school level. These differences in expectations of teacher behavior in other grade levels or alternative educational settings could change the interpretation of misbehaviors. Teachers may also misbehave in different ways outside of the university/college setting as well. For instance, one of the indolent behaviors is to end class early or arrive to class late. This behavior cannot occur in a pre-Kindergarten to $12^{\text {th }}$ grade situation. The misbehaviors then would be different from the 
current typology.

Alternative teaching events should be addressed as well. For instance, medical education is a specialized education system that does not follow a similar format of college/university teaching. Technical and professional development situations would also need to be researched.

Research should also examine how teacher characteristics may play a role in the interpretation of misbehaviors. This study utilized a female instructor in her 50's. This may have influenced the interpretation of misbehaviors and also how the misbehaviors were communicated. Future research should address how sex and age of the instructor may change these perceptions.

Researchers should also address how the class itself would be influenced by teacher misbehaviors. Student experience classes differently whether it is the topic addressed by the class or if the class is in their major, the misbehaviors may be interpreted differently. For instance, if the class were in the students' major would teacher misbehaviors have a more negative impact on students?

Another question researchers should examine is when does misbehavior become detrimental? At what point does it affect learning, motivation, self-efficacy, and curiosity. This would address the potential threshold effect that could occur with misbehaviors. By implementing a more qualitative method, this question may be addressed better in an actual classroom setting. By conducting ethnographic research, focus groups, or even action research a researcher may be able to explore the relationship of how time influences misbehavior perceptions. As time passes a teacher can potentially build a rapport and misbehaviors may be interpreted differently because of the rapport. The building of a rapport with students exemplifies 
the contextual nature of the teaching situation that is often better addressed through qualitative means rather than quantitative. This acknowledgment of the contextual nature of teaching may result in better understanding of misbehaviors for the classroom teacher. The research may give us more insight into the identification of true misbehavior in the classroom setting to see if they are actually occurring.

Future research should also examine potential solutions for teacher misbehavior. As we learn more about misbehaviors we should also examine potential ways of avoiding these problem behaviors or ways to correct the detrimental effect on students. Studies also need to be done in a true classroom setting where misbehavior is present to see how it can truly affect learning outcomes and variables that influence learning. We may be able to identify student behaviors that indicate that a teacher is misbehaving. By identifying these behaviors the teacher can adjust to the students' learning needs and avoid behaviors that may be considered teacher misbehaviors. By taking this research to the classroom setting, we could help teachers be better teachers and help students have a better learning experience.

Implications of this study are that more research needs to be done to clarify how teacher misbehaviors truly influence students' learning. An emerging variable needs to be addressed in misbehavior research: engagement. The results found here indicate that infrequent misbehaviors may not have as detrimental an impact in the short term as previously thought; because this varies from previous research, further explanation of these findings is needed. Most importantly these results do not support teacher misbehaviors as positive or behavior that should occur in the classroom rather it indicates that under the limited circumstances it may not be detrimental in the short term. 


\section{References}

Abu-Jaber, M. \& Qutami, N. (1998). Students’ self-efficacy of computer through the use of cognitive thinking style. International Journal of Instructional Media, 25, 263-277.

Anderson, C. M., \& Martin, M. M. (1995). Communication motives of assertive and responsive communicators. Communication Research Reports, 12 186-191.

Banfield, S. R. (2008, May). When are teacher misbehaviors appropriate? Paper presented at the Eastern Communication Association, Pittsburgh, PA.

Banfield, S. R., McCroskey, J. C., \& Richmond, V. P. (2006). The effect of teacher misbehaviors on teacher credibility and affect for teacher. Communication Education, 55, 63-72.

Beatty, M. J., Forst, E. C., \& Stewart, R. A. (1986). Communication apprehension and motivation as predictors of public speaking duration. Communication Education, 35, 143146.

Bong, M. (1997). Generality of academic self-efficacy judgments: Evidence of hierarchical relations. Journal of Educational Psychology, 89, 696-709.

Boykin, A. W., \& Harackiewicz, J. (1981). Epistemic curiosity and incidental recognition in relation to degree of uncertainty: Some general trends and intersubject differences. British Journal of Psychology, 72, 65-72.

Boyle, G. J. (1983). Critical review of state-trait curiosity test development. Motivation and Emotion, 7, 377-397.

Brophy, J. (1987). Synthesis of research on strategies for motivating students to learn. Educational Leadership, 45, 40-48.

Chemers, M. M., Hu, L., \& Garcia, B. F. (2001). Academic self-efficacy and first-year college 
student performance and adjustment. Journal of Educational Psychology, 93, 55-64.

Chesebro, J., \& McCroskey, J. C. (2000). The relationship between students’ reports of learning and their actual recall of lecture material: A validity test. Communication Education, 49, 297-301.

Christensen, L. J., \& Menzel, K. E. (1998). The linear relationship between student reports of teacher immediacy behaviors and perceptions of state motivation, and of cognitive, affective, and behavioral learning. Communication Education, 47, 82-90.

Christie, V., \& Segrin, C. (1998). The influence of self-efficacy and gender on the performance of social and nonsocial tasks. Journal of Applied Communication Research, 26, 374-389.

Christophel, D. M. (1990). The relationship among teacher immediacy behaviors, student motivation, and learning. Communication Education, 39, 323-340.

Deci, E. L., Vallerand, R. J., Pelletier, L. G., \& Ryan, R. M. (1991). Motivation and education: The self-determination perspective. Educational Psychologist, 26, 325-346.

Dolin, D. J. (1995) Ain't misbehavin': A study of teacher misbehaviors, related communication behaviors, and student resistance. Unpublished doctoral dissertation, West Virginia University, Morgantown, WV.

Frymier. A. B. (1993a). The impact of teacher immediacy on students' motivation: Is it the same for all students? Communication Quarterly, 41, 454-464.

Frymier, A. B. (1993b). The relationships among communication apprehension, immediacy, and motivation to study. Communication Reports, 6, 8-17.

Frymier, A. B., Shulman, G. M., \& Houser, M. (1996). The development of a learner empowerment measure. Communication Education, 45, 181-199. 
Frymier, A. B., \& Thompson, C. A. (1992). Perceived teacher affinity-seeking in relation to perceived teacher credibility. Communication Education, 41, 388-399.

Gorham, J., \& Christophel, D. M. (1992). Students' perceptions of teacher behaviors as motivating and demotivating factors in college classes. Communication Quarterly, 40, 239-252.

Handelsman, M. M., Briggs, W. L., Sullivan, N., \& Towler, A. (2005). A measure of college student course engagement. The Journal of Educational Research, 98, 184-191.

Henderson, B., \& Moore, S. G. (1980). Children’s responses to objects differing in novelty in relation to level of curiosity and adult behavior. Child Development, 51, 457-465.

Hinkle, D. E., Wiersma, W., \& Jurs, S. G. (2005). Applied statistics for the behavioral sciences ( $5^{\text {th }}$ ed.). Boston: Houghton Mifflin Company.

Houser, M. L. (2006). Expectancy violations of instructor communication as predictors of motivation and learning: A comparison of traditional and nontraditional students. Communication Quarterly, 54, 331-349.

Huang, L. S. (2003). Ten pointers for enhancing learners' motivation. Business Communication Quarterly, 66, 90-97.

Kearney, P., Plax, T. G., \& Allen, T. H. (2002). Understanding student reactions to teachers who misbehave. In J. L. Chesebro \& J. C. McCroskey (Eds.), Communication for teachers (pp. 127-149). Boston, MA: Allyn \& Bacon.

Kearney, P., Plax, T. G., Hays, L. R., \& Ivey, M. J. (1991). College teacher misbehaviors: What students’ don’t like about what teachers say or do. Communication Quarterly, 39, 309324. 
Kelley, D. H., \& Gorham, J. (1988). Effects of immediacy on recall of information. Communication Education, 37, 198-207.

Kerssen-Griep, J. (2001). Teacher communication activities relevant to student motivation: Classroom facework and instructional communication competence. Communication Education, 50, 256-273.

Kerssen-Griep, J., Hess, J. A., \& Trees, A. R. (2003). Sustaining the desire to learn: Dimensions of perceived instructional facework related to student involvement and motivation to learn. Western Journal of Communication, 67, 357-381.

Kim, A., \& Park, I. (2000, April). Hierarchical structure of self-efficacy in terms of generality levels and its relations to academic performance: General, academic, domain-specific, and subject-specific self-efficacy. Paper presented at the Annual Meeting of the American Educational Research Association. New Orleans, LA.

Klein, D. C. D., O’Neil, H. F. Jr., Dennis, R. A., \& Baker, E. L. (1997, March). The five families of cognitive learning: A context in which to conduct cognitive demands analyses of innovative technologies. Paper presented at the annual meeting of the American Educational Research Association, Chicago, IL.

Kreitler, S., Zigler, E., \& Kreitler, H. (1984). Curiosity and demographic factors as determinants of children's probability learning strategies. The Journal of Genetic Psychology, 145, 6175.

Lent, R. W., Brown, S. D., \& Gore Jr., P. A. (1997). Discriminant and predictive validity of academic self-concept, academic self-efficacy, and mathematics-specific self-efficacy. Journal of Counseling Psychology, 44, 307-315. 
Lowry, N., \& Johnson, D. W. (1981). Effects of controversy on epistemic curiosity, achievement, and attitudes. The Journal of Social Psychology, 115, 31-43.

Maier, S. R., \& Curtin, P. A. (2005). Self-efficacy theory: A prescriptive model for teaching research methods. Journalism \& Mass Communication Educator, 59, 352-364.

Mehrabian, A. (1969). Some referents and measures of nonverbal behavior. Behavioral Research Methods and Instrumentation, 1, 213-217.

Minuchin, P. (1971). Correlates of curiosity and exploratory behavior in preschool disadvantaged children. Child Development, 42, 939-951.

Mottet, T. P., Beebe, S. A., Raffeld, P. C., \& Medlock, A. L. (2004). The effects of student verbal and nonverbal responsiveness on teacher self-efficacy and job satisfaction. Communication Education, 53, 150-163.

Mottet, T. P., Martin, M., \& Myers, S. A. (2004). Relationships among perceived instructor verbal approach and avoidance relational strategies and students’ motives for communicating with their instructors. Communication Education, 53, 116-122.

Naylor, F. D. (1981). A state-trait curiosity inventory. Australian Psychologist, 16, 172-183. Pajares, F. (1995). Self-efficacy in academic settings. Paper presented at the Annual Meeting of the American Educational Research Association, San Francisco, CA.

Paulsel, M. L., \& Terrazas, V. A. (2002, November). The effects of teacher immediacy, use of behavior-alteration techniques, and misbehavior on student perceptions of teacher power. Paper presented at the annual meeting of the National Communication Association, New Orleans, LA.

Pogue, L. L., \& AhYun, K. (2006). The effect of teacher nonverbal immediacy and credibility on 
student motivation and affective learning. Communication Education, 55, 331-344.

Reio Jr, T. G., Petrosko, J. M., Wiswell, A. K., \& Thongsukmag, J. (2006). The measurement and conceptualization of curiosity. The Journal of Genetic Psychology, 167, 117-135.

Richmond, V. P. (1990). Communication in the classroom: Power and motivation. Communication Education, 39, 181-195.

Richmond, V. P., Wrench, J. S., \& Gorham, J. (2001). Communication, affect, and learning in the classroom. Action, MA: Tapestry Press.

Rodriguez, J. I., Plax, T. G., \& Kearney, P. (1996). Clarifying the relationship between teacher nonverbal immediacy and student cognitive learning: Affective learning as the central causal mediator. Communication Education, 45, 293-305.

Ryan, A. M., Gheen, M. H., \& Midgley, C. (1998). Why do some students avoid asking for help? An examination of the interplay among students’ academic efficacy, teachers’ socialemotional role, and the classroom goal structure. Journal of Educational Psychology, 90, 528-535.

Saxe, R. M., \& Stollak, G. E. (1971). Curiosity and the parent-child relationship. Child Development, 42, 373-384.

Schunk, D. H. (1991). Self-efficacy and academic motivation. Educational Psychologist, 26, 207-231.

Skinner, E. A., \& Belmont, M. J. (1993). Motivation in the classroom: Reciprocal effects of teacher behavior and student engagement across the school year. Journal of Educational Psychology, 85, 571-581.

Thweatt, K. S. (1996). Immediacy and teacher misbehaviors. Unpublished masters thesis, West 
Virginia University, Morgantown.

Thweatt, K. S. (1999). The effect of teacher immediacy, affinity-seeking, and misbehavior on instructional outcomes. Unpublished doctoral dissertation, West Virginia University, Morgantown, WV.

Thweatt, K. S., \& McCroskey, J. C. (1996). Teacher nonimmediacy and misbehavior: Unintentional negative communication. Communication Research Reports, 13, 198-204.

Thweatt, K. S., \& McCroskey, J. C. (1997). Teacher nonimmediacy and misbehavior: unintentional negative communication. Communication Research Reports, 13, 198-204.

Thweatt, K. S., \& McCroskey, J. C. (1998). The impact of teacher immediacy and misbehavior on teacher credibility. Communication Education, 47, 348-358.

Toale, M. C. (2001). Teacher clarity and teacher misbehaviors: Relationships with students' affective learning and teacher credibility. Unpublished doctoral dissertation, West Virginia University, Morgantown,, WV.

Wanzer, M. B., \& McCroskey, J. C. (1998). Teacher socio-communicative style as a correlate of student affect toward teacher and course material. Communication Education, 47, 43-52.

Weber, K. (2003). The relationship of interest to internal and external motivation. Communication Research Reports, 20, 376-383.

Weber, K., Martin, M. M., \& Cayanus, J. L. (2005). Student interest: A two-study reexamination of the concept. Communication Quarterly, 53, 71-86.

Wiltse, E. M. (2002). Correlates of college students’ use of instructors’ comments. Journalism \& Mass Communication Education, 57, 126-138.

Wlodkowski, R. J. (1984). Motivation and teaching. Washington, D.C.: National Education 
Association.

Zhang, Q. (2007). Teacher misbehaviors as learning demotivators in college classrooms: A cross-cultural investigation in China, Germany, Japan, and the United States. Communication Education, 56, 209-227. 


\section{Appendix A \\ Condition A: Good Teacher}

During this lecture please make good eye contact, smiling, excited about what is being taught. Get students involved by asking them for examples. You are going to be a good teacher. Computer-mediated communication

I. What is Computer-Mediated Communication? (Wait for student answer and then give positive response like good or that is correct)

a. An exchange of information between persons by way of computer networks.

b. The exchange of information can be:

i. Real time communication or synchronous: people communicating with each other at the same time. (ask for example once again giving positive response to student who answers)

ii. Asynchronous: this means that people are communicating at different times. (ask for example giving positive response)

II. Why do we need to know about CMC? (get students to respond to this question before moving on, remember to make good eye contact, and smile, you like what you are teaching)

a. Prevalence of use in our society.

i. The number grows everyday but it is estimated that 233 million people use the internet in the US alone (www.internetworldstats.com)

ii. Over 165 countries are connected to the Internet

b. Access to billions of WebPages: there is an estimated 29.7 billion papers as of February 2007.

c. Unparalleled communication capacities.

i. Voice, text, video (many modes of communication can occur)

ii. Synchronous, asynchronous (have the ability to instantly communicate or leave communication for others to find)

iii. Very inexpensive

iv. Business, play, and education all occur (people use for many different reasons)

III. Comparing CMC to other mediums (explain that this can help students easily understand the communication capacities, remember to get the students engaged and smile and be enthusiastic throughout)

a. $\mathrm{CMC}$ can be like writing a letter or memo

i. One-to-one: with the writer delivering a message directly to a reader.

ii. (Ask for examples before offering your own) Ex: e-mail, most e-mail applications follow a memo format and function like letters and memos, a common way of responding rhetorically to a situation or "genre"

b. $\mathrm{CMC}$ can be like creating a mass mailing or group mailing

i. One-to-many: with the writer delivering a message directly to many readers

ii. (Ask for examples before offering your own) Ex: listservs and/or e-mail: Listservs enable subscription-only members to send and retrieve an email message to one address, which in turn forwards that message to the email addresses of all other members.

C. CMC can be like posting a message on a bulletin board or kiosk.

i. One-to-many: writer leaving a test so that others may wander by and read it.

ii. (Ask for examples before offering your own) Ex: Online bulletin board systems: these often appear as web pages where a reader can browse through a 
collection of messages left by others. Weblogs, or "blogs" are web-delivered and computer-mediated records of textual communication, the rhetorical interaction within a scene or "situation"

d. CMC can be like engaging in a face-to-face conversation.

i. One-to-many or many-to-many: two or more people can meet converse at the same time. All participants must be "present" simultaneously.

ii. (Ask for example before offering your own) Ex: chat rooms and MUDs/MOOs: applications allow participants to send messages, which others see immediately. MUDs/MOOs can be used individually and in small-groups, the scene of computer mediated composition.

IV. Systems for Computer-Mediated Communication (These are programs or ways that individuals communicate via the computer, indicate that many of the students use these systems and that it is relevant to their lives, remember to use positive cues such as positive responses to students, smiles, and eye contact)

a. E-mail: The user produces, sends, and receives mail at a computer.

i. The messages will be stored on a server and the user can get mail when you want to.

ii. Usually the message will contain only text, but possible files can be attached that include images, audio, etc.

iii. (ask for examples, provide positive responses to student answers) School accounts, aol.com, etc

b. World Wide Web (WWW) is the part of the Internet that brings together all of the different kinds of online resources available via word processor-like documents.

i. Web documents, which can integrate text, graphics, sound, and motion, usually contain links to other Internet resources.

ii. It can be synchronous or asynchronous.

iii. (ask for popular examples, provide positive responses to student answers) Ex: Any web page that begins with "www"

c. Newsgroups or bulletin board systems: are public discussions on more than 10,000 different topics on the Internet.

i. Single copies of articles are stored in a publicly accessible place.

ii. Users can read what others have written, respond publicly or privately to the article's author, and post new ideas, questions or requests to the newsgroup.

iii. (ask for examples, provide positive responses to student answers) Netscape news, MSN news

(indicate that while these are wide spread systems the rest may not have been used by students yet but may be used in their future in their jobs as you continue through have students think how they might use these in their business of job later making the information applicable to their lives)

d. Computer conferencing: allows a group of people to hold a discussion by computer.

i. Members of the group can use the system to post messages to the whole group, and discussions can thus take place over a period of time.

ii. Have the possibility for real time interaction.

iii. The members of the group are in a separate network.

iv. (ask for examples, provide positive feedback) Ex: First class

e. Audio conferencing: is the simultaneous connection of many different telephone lines. 
i. A group of people can have communication with each other by way of the telephone.

ii. (ask for examples, provide positive feedback) Ex: Microsoft Netmeeting

f. Video conferencing: real time video and audio communication between people in difference locations.

i. A video camera, a monitor and some features to control them are needed to send and receive the information.

ii. (ask for example, provide positive feedback) Ex: A system for videoconferencing is CU-SeeMee

g. Voice mail systems: electronic mail systems for spoken messages.

i. The telephone can also be used to send messages and receive them so a computer is not necessary.

ii. (ask for examples, provide positive feedback) Ex: IPhone

h. IRC: is a mode of interaction on the Internet in which people are able to communicate synchronistically on different 'channels' from disparate locations.

i. This is text-based, but is possible to send images as an attachment.

ii. (ask for examples, provide positive feedback) Ex: Microsoft Netmeeting

i. MUD/MOO: Multi User Dungeons/MUD Object Oriented.

i. It is a synchronous system in which users can interact in real time by typing text.

ii. It is virtual reality because it describes objects like rooms or buildings and users that are in the same place that you are.

iii. You are a character in this environment that can take actions by typing commands like walk, whisper, kick, etc.

iv. (ask for examples, provide positive feedback) Ex: Multiplayer computer game: World of Warcraft

j. Whiteboard environments: are virtual meetings where each participant can use the mouse to draw sketches on the whiteboard.

i. As each user is drawing, every other user connected to the server sees the updates almost immediately.

ii. Most have a chat window where participants can type messages to each other.

iii. (ask for examples, provide positive feedback) Ex: Microsoft Netmeeting

k. Work flow applications: have intrinsic and interaction rules that embody the business process.

i. Work flow management rules underlie the movement of data from person to machine, control the manner in which the data is processed, and control the way data is stored.

ii. (ask for examples, provide positive feedback) Ex: Lotus Notes

All of these CMC systems you will need a common computer, a network connection, and special software.

$\mathrm{V}$. Media supported by computer-mediated communication (indicate that one of the advantages to $\mathrm{CMC}$ is that many different types of media can be utilized to send your message where outside of CMC you may be limited to only one type of media or have to use multiple applications or machines to achieve the same process) (remember to continue using goodeye contact, engage the students in the lesson, smile, be enthusiastic about what you are saying) 
a. 5 kinds of media are distinguished here (get students to provide examples and uses for each type of media)

i. Text: consists of letters, numbers, punctuations, special characters, and controls.

ii. Graphics: are lines, circles, boxes, shading, fill colors, etc.

iii. Images are still pictures, expressed as the colors of many small individual picture elements (pixels); this can be a photograph or paintings.

iv. Audio: consists of sound including voice, music, and special effects.

V. Video consists of successive pictures presented sufficiently rapidly to give the appearance of smooth motion.

(Wrap up by stating that you enjoyed the opportunity to come and speak with the students about $\mathrm{CMC}$ and that it is important that students understand the possibilities of communication in $\mathrm{CMC}$ because we are relying more and more on the computer to communicate with others) 
Appendix B

Condition B: Incompetent

During this lecture please speak in a monotone, slow manner. You should have no animation and make the lecture boring. Do not offer any further explanation if a student asks a question. Before starting state that the information that you are giving to them is pretty basic and dry. Do not move from behind the podium and pick a point at the back of the room to look at if you are not looking at the lecture notes. Do not give students the chance to participate, so do not ask for examples, this does not allow the students to interact in the teaching lesson.

I. What is Computer-Mediated Communication? (remember monotone, you are not excited about being there and you are NOT making it excited for the students)

a. An exchange of information between persons by way of computer networks.

b. The exchange of information can be:

i. Real time communication or synchronous: people communicating with each other at the same time. (do not offer further explanation)

ii. Asynchronous: this means that people are communicating at different times. (do not offer further explanation)

II. Why do we need to know about CMC? (Make sure that you are not enthusiastic, do not move around and have minimal animation to gestures and features)

a. Prevalence of use in our society.

i. The number grows everyday but it is estimated that 233 million people use the internet in the US alone (www.internetworldstats.com)

ii. Over 165 countries are connected to the Internet

b. Access to billions of WebPages: there is an estimated 29.7 billion papers as of February 2007.

c. Unparalleled communication capacities.

i. Voice, text, video (many modes of communication can occur)

ii. Synchronous, asynchronous (have the ability to instantly communicate or leave communication for others to find)

iii. Very inexpensive

iv. Business, play, and education all occur (people use for many different reasons)

III. Comparing CMC to other mediums (indicate that these are obvious applications that can be compared, keeping your tone dry and monotone, no animation)

a. (monotone) $\mathrm{CMC}$ can be like writing a letter or memo

i. One-to-one: with the writer delivering a message directly to a reader.

ii. Ex: e-mail, most e-mail applications follow a memo format and function like letters and memos, a common way of responding rhetorically to a situation or "genre"

b. (monotone) $\mathrm{CMC}$ can be like creating a mass mailing or group mailing

i. One-to-many: with the writer delivering a message directly to many readers

ii. Ex: listservs and/or e-mail: Listservs enable subscription-only members to send and retrieve an email message to one address, which in turn forwards that message to the email addresses of all other members.

c. (monotone) $\mathrm{CMC}$ can be like posting a message on a bulletin board or kiosk.

i. One-to-many: writer leaving a test so that others may wander by and read it. 
ii. Ex: Online bulletin board systems: these often appear as web pages where a reader can browse through a collection of messages left by others. Weblogs, or "blogs" are web-delivered and computer-mediated records of textual communication, the rhetorical interaction within a scene or "situation"

d. (monotone) CMC can be like engaging in a face-to-face conversation.

i. One-to-many or many-to-many: two or more people can meet converse at the same time. All participants must be "present" simultaneously.

ii. Ex: chat rooms and MUDs/MOOs: applications allow participants to send messages, which others see immediately. MUDs/MOOs can be used individually and in small-groups, the scene of computer mediated composition.

IV. Systems for Computer-Mediated Communication (remember that this is not fun and should not be fun for the students, you are making this as boring as possible, remember no movements and speak slowly with monotone)

a. (monotone, no movement) E-mail: The user produces, sends, and receives mail at a computer.

i. The messages will be stored on a server and the user can get mail when you want to.

ii. Usually the message will contain only text, but possible files can be attached that include images, audio, etc.

iii. School accounts, aol.com, etc

b. (monotone, no movement) World Wide Web (WWW) is the part of the Internet that brings together all of the different kinds of online resources available via word processor-like documents.

i. Web documents, which can integrate text, graphics, sound, and motion, usually contain links to other Internet resources.

ii. It can be synchronous or asynchronous.

iii. Ex: Any web page that begins with "www"

c. (monotone, no movement) Newsgroups or bulletin board systems: are public discussions on more than 10,000 different topics on the Internet.

i. Single copies of articles are stored in a publicly accessible place.

ii. Users can read what others have written, respond publicly or privately to the article's author, and post new ideas, questions or requests to the newsgroup.

iii. Netscape news, MSN news

d. (monotone, no movement) Computer conferencing: allows a group of people to hold a discussion by computer.

i. Members of the group can use the system to post messages to the whole group, and discussions can thus take place over a period of time.

ii. Have the possibility for real time interaction.

iii. The members of the group are in a separate network.

iv. Ex: First class

e. (monotone, no movement) Audio conferencing: is the simultaneous connection of many different telephone lines.

i. A group of people can have communication with each other by way of the telephone.

ii. Ex: Microsoft Netmeeting 
f. (monotone, no movement) Video conferencing: real time video and audio communication between people in difference locations.

i. A video camera, a monitor and some features to control them are needed to send and receive the information.

ii. Ex: A system for videoconferencing is CU-SeeMee

g. (monotone, no movement) Voice mail systems: electronic mail systems for spoken messages.

i. The telephone can also be used to send messages and receive them so a computer is not necessary.

ii. Ex: IPhone

h. (monotone, no movement) IRC: is a mode of interaction on the Internet in which people are able to communicate synchronistically on different 'channels' from disparate locations.

i. This is text-based, but is possible to send images as an attachment.

ii. Ex: Microsoft Netmeeting

i. (monotone, no movement) MUD/MOO: Multi User Dungeons/MUD Object Oriented.

i. It is a synchronous system in which users can interact in real time by typing text.

ii. It is virtual reality because it describes objects like rooms or buildings and users that are in the same place that you are.

iii. You are a character in this environment that can take actions by typing commands like walk, whisper, kick, etc.

iv. Ex: Multiplayer computer game: World of Warcraft

j. (monotone, no movement) Whiteboard environments: are virtual meetings where each participant can use the mouse to draw sketches on the whiteboard.

i. As each user is drawing, every other user connected to the server sees the updates almost immediately.

ii. Most have a chat window where participants can type messages to each other.

iii. Ex: Microsoft Netmeeting

k. Work flow applications: have intrinsic and interaction rules that embody the business process.

i. Work flow management rules underlie the movement of data from person to machine, control the manner in which the data is processed, and control the way data is stored.

ii. Ex: Lotus Notes

All of these CMC systems you will need a common computer, a network connection, and special software.

V. Media supported by computer-mediated communication

a. (monotone, no movement) 5 kinds of media are distinguished here

i. Text: consists of letters, numbers, punctuations, special characters, and controls.

ii. Graphics: are lines, circles, boxes, shading, fill colors, etc.

iii. Images are still pictures, expressed as the colors of many small individual picture elements (pixels); this can be a photograph or paintings.

iv. Audio: consists of sound including voice, music, and special effects.

v. Video consists of successive pictures presented sufficiently rapidly to give the appearance of smooth motion. Thank them for their time and that is it. 
Appendix C

Condition C: Indolent

Show up late to this lecture. When you first get there shuffle papers acting disorganized. You are the stereotypical absent minded professor. Before beginning ask now what are we here to talk about looking at the students expectantly like they would know but they don't then say when there is no answer um, um, um, right I will be talking about CMC (this reiterates that you are a little lost or confused). Say you will complete this lesson as quickly as possible that means that you need to speak quickly as well throughout the lesson).

I. What is Computer-Mediated Communication?

a. An exchange of information between persons by way of computer networks.

b. The exchange of information can be:

i. Real time communication or synchronous: people communicating with each other at the same time. (ask for examples)

ii. Asynchronous: this means that people are communicating at different times. (ask for examples)

II. Comparing CMC to other mediums

a. CMC can be like writing a letter or memo (YOU WILL ACT DISORGANIZED AND BEGIN TEACHING THIS PART THEN INDICATE THAT YOU WANT TO START WITH SOMETHING ELSE AND WILL COME BACK TO THIS)

III. Why do we need to know about CMC? (ask for reasons, then hurry them along so that you can get done, so that means maybe cutting students answers short)

a. Prevalence of use in our society.

i. The number grows everyday but it is estimated that 233 million people use the internet in the US alone (www.internetworldstats.com)

ii. Over 165 countries are connected to the Internet

b. Access to billions of WebPages: there is an estimated 29.7 billion pages as of February 2007.

c. Unparalleled communication capacities.

i. Voice, text, video (many modes of communication can occur)

ii. Synchronous, asynchronous (have the ability to instantly communicate or leave communication for others to find)

iii. Very inexpensive

iv. Business, play, and education all occur (people use for many different reasons)

IV. Comparing CMC to other mediums (here because you are in a hurry only give the example not the explanation of the example)

a. $\mathrm{CMC}$ can be like writing a letter or memo

i. One-to-one: with the writer delivering a message directly to a reader.

ii. Ex: e-mail, (This is the explanation of the example do not give this: most e-mail applications follow a memo format and function like letters and memos, a common way of responding rhetorically to a situation or "genre")

b. $\mathrm{CMC}$ can be like creating a mass mailing or group mailing

i. One-to-many: with the writer delivering a message directly to many readers

ii. Ex: listservs and/or e-mail: (This is the explanation of the example do not give this: Listservs enable subscription-only members to send and retrieve an email 
message to one address, which in turn forwards that message to the email addresses of all other members.)

c. $\mathrm{CMC}$ can be like posting a message on a bulletin board or kiosk.

i. One-to-many: writer leaving a test so that others may wander by and read it.

ii. Ex: Online bulletin board systems: (This is the explanation of the example do not give this: these often appear as web pages where a reader can browse through a collection of messages left by others. Weblogs, or "blogs" are web-delivered and computer-mediated records of textual communication, the rhetorical interaction within a scene or "situation")

d. CMC can be like engaging in a face-to-face conversation.

i. One-to-many or many-to-many: two or more people can meet converse at the same time. All participants must be "present" simultaneously.

ii. Ex: chat rooms and MUDs/MOOs: (This is the explanation of the example do not give this: applications allow participants to send messages which others see immediately. MUDs/MOOs can be used individually and in small-groups, the scene of computer mediated composition. )

V. Systems for Computer-Mediated Communication

a. E-mail: The user produces, sends, and receives mail at a computer.

$i$. (Do not give the further explanation just give the concept definition because you are trying to get done with the lesson faster, so do not give the following information. The messages will be stored on a server and the user can get mail when you want to.

ii. Usually the message will contain only text, but possible files can be attached that include images, audio, etc.

iii. School accounts, aol.com, etc)

b. World Wide Web (WWW) is the part of the Internet that brings together all of the different kinds of online resources available via word processor-like documents.

i. (Do not give the further explanation just give the concept definition because you are trying to get done with the lesson faster, so do not give the following information. Web documents, which can integrate text, graphics, sound, and motion, usually contain links to other Internet resources.

ii. It can be synchronous or asynchronous.

iii. Ex: Any web page that begins with "www")

c. Newsgroups or bulletin board systems: are public discussions on more than 10,000 different topics on the Internet.

i. (Do not give the further explanation just give the concept definition because you are trying to get done with the lesson faster, so do not give the following information. Single copies of articles are stored in a publicly accessible place.

ii. Users can read what others have written, respond publicly or privately to the article's author, and post new ideas, questions or requests to the newsgroup.

iii. Netscape news, MSN news)

d. Computer conferencing: allows a group of people to hold a discussion by computer.

$i$. (Do not give the further explanation just give the concept definition because you are trying to get done with the lesson faster, so do not give the following information. Members of the group can use the system to post messages to the whole group, and discussions can thus take place over a period of time.

ii. Have the possibility for real time interaction. 
iii. The members of the group are in a separate network.

iv. Ex: First class)

e. Audio conferencing: is the simultaneous connection of many different telephone lines.

$i$. (Do not give the further explanation just give the concept definition because you are trying to get done with the lesson faster, so do not give the following information. A group of people can have communication with each other by way of the telephone.

ii. Ex: Microsoft Netmeeting)

f. Video conferencing: real time video and audio communication between people in difference locations.

i. (Do not give the further explanation just give the concept definition because you are trying to get done with the lesson faster, so do not give the following information. A video camera, a monitor and some features to control them are needed to send and receive the information.

ii. Ex: A system for videoconferencing is CU-SeeMee)

g. Voice mail systems: electronic mail systems for spoken messages.

i. (Do not give the further explanation just give the concept definition because you are trying to get done with the lesson faster, so do not give the following information. The telephone can also be used to send messages and receive them so a computer is not necessary.

ii. Ex: IPhone)

h. IRC: is a mode of interaction on the Internet in which people are able to communicate synchronistically on different 'channels' from disparate locations.

i. (Do not give the further explanation just give the concept definition because you are trying to get done with the lesson faster, so do not give the following information. This is text-based, but is possible to send images as an attachment.

ii. Ex: Microsoft Netmeeting)

i. MUD/MOO: Multi User Dungeons/MUD Object Oriented.

i. It is a synchronous system in which users can interact in real time by typing text.

ii. (Do not give the further explanation just give the concept definition because you are trying to get done with the lesson faster, so do not give the following information. It is virtual reality because it describes objects like rooms or buildings and users that are in the same place that you are.

iii. You are a character in this environment that can take actions by typing commands like walk, whisper, kick, etc.

iv. Ex: Multiplayer computer game: World of Warcraft )

j. Whiteboard environments: are virtual meetings where each participant can use the mouse to draw sketches on the whiteboard.

i. (Do not give the further explanation just give the concept definition because you are trying to get done with the lesson faster, so do not give the following information. As each user is drawing, every other user connected to the server sees the updates almost immediately.

ii. Most have a chat window where participants can type messages to each other.

iii. Ex: Microsoft Netmeeting)

k. Work flow applications: have intrinsic and interaction rules that embody the business process. 
i. (Do not give the further explanation just give the concept definition because you are trying to get done with the lesson faster, so do not give the following information. Work flow management rules underlie the movement of data from person to machine, control the manner in which the data is processed, and control the way data is stored.

ii. Ex: Lotus Notes)

All of these CMC systems you will need a common computer, a network connection, and special software.

VI. Media supported by computer-mediated communication

a. 5 kinds of media are distinguished here

i. Text: consists of letters, numbers, punctuations, special characters, and controls.

ii. Graphics: are lines, circles, boxes, shading, fill colors, etc.

iii. Images are still pictures, expressed as the colors of many small individual picture elements (pixels); this can be a photograph or paintings.

iv. Audio: consists of sound including voice, music, and special effects.

V. Video consists of successive pictures presented sufficiently rapidly to give the appearance of smooth motion.

Indicate at the end of the lesson that you are done early and that you are glad that you don't have to grade any papers or anything because it would be too much work. 


\section{Appendix D \\ Condition D: Offensive}

Begin the class by stating that "I am dumbing down this information for you" You are an offensive instructor, so if students ask questions use sarcasm indicating that the question is not worth your time or a dumb question.

I. What is Computer-Mediated Communication?

a. An exchange of information between persons by way of computer networks.

b. The exchange of information can be:

i. Real time communication or synchronous: people communicating with each other at the same time. (ask for examples, and if people give an answer if it is wrong roll your eyes and say rudely wrong if it is a right answer roll your eyes and indicate with sarcasm that you are amazed that they got it right continue this behavior every time that you ask for a response and get one from the students)

ii. Asynchronous: this means that people are communicating at different times. (ask for example, sarcasm and eye role)

II. Why do we need to know about CMC? (ask for example, sarcasm and eye role)

a. Prevalence of use in our society.

i. The number grows everyday but it is estimated that 233 million people use the internet in the US alone (www.internetworldstats.com)

ii. Over 165 countries are connected to the Internet

b. Access to billions of WebPages: there is an estimated 29.7 billion papers as of February 2007.

c. Unparalleled communication capacities.

i. Voice, text, video (many modes of communication can occur)

ii. Synchronous, asynchronous (have the ability to instantly communicate or leave communication for others to find)

iii. Very inexpensive

iv. Business, play, and education all occur (people use for many different reasons)

III. Comparing CMC to other mediums (indicate that you compare $\mathrm{CMC}$ to other mediums so that they will be able to understand the concept that is beyond their reach otherwise)

a. CMC can be like writing a letter or memo (ask for why it would be like a letter or memo, sarcasm and eye role)

i. One-to-one: with the writer delivering a message directly to a reader.

ii. Ex: e-mail, most e-mail applications follow a memo format and function like letters and memos, a common way of responding rhetorically to a situation or "genre"

b. CMC can be like creating a mass mailing or group mailing (ask for why it would be like a mass mailing or group mailing, sarcasm and eye role)

i. One-to-many: with the writer delivering a message directly to many readers

ii. Ex: listservs and/or e-mail: Listservs enable subscription-only members to send and retrieve an email message to one address, which in turn forwards that message to the email addresses of all other members.

c. CMC can be like posting a message on a bulletin board or kiosk. (ask for why it would be like a bulletin board or kiosk, sarcasm and eye role)

i. One-to-many: writer leaving a test so that others may wander by and read it. 
ii. Ex: Online bulletin board systems: these often appear as web pages where a reader can browse through a collection of messages left by others. Weblogs, or "blogs" are web-delivered and computer-mediated records of textual communication, the rhetorical interaction within a scene or "situation"

d. CMC can be like engaging in a face-to-face conversation. (ask for why it would be like a face-to-face conversation, sarcasm and eye role)

i. One-to-many or many-to-many: two or more people can meet converse at the same time. All participants must be "present" simultaneously.

ii. Ex: chat rooms and MUDs/MOOs: applications allow participants to send messages which others see immediately. MUDs/MOOs can be used individually and in small-groups, the scene of computer mediated composition.

IV. Systems for Computer-Mediated Communication (Indicate that you will explain each system in detail because you now they are not smart enough to fully grasp the concept, make sure to give all details)

a. E-mail: The user produces, sends, and receives mail at a computer.

i. The messages will be stored on a server and the user can get mail when you want to.

ii. Usually the message will contain only text, but possible files can be attached that include images, audio, etc.

iii. (ask for example, sarcasm and eye role) School accounts, aol.com, etc

b. World Wide Web (WWW) is the part of the Internet that brings together all of the different kinds of online resources available via word processor-like documents.

i. Web documents, which can integrate text, graphics, sound, and motion, usually contain links to other Internet resources.

ii. It can be synchronous or asynchronous.

iii. (ask for example, sarcasm and eye role) Ex: Any web page that begins with "www"

c. Newsgroups or bulletin board systems: are public discussions on more than 10,000 different topics on the Internet.

i. Single copies of articles are stored in a publicly accessible place.

ii. Users can read what others have written, respond publicly or privately to the article's author, and post new ideas, questions or requests to the newsgroup.

iii. (ask for example, sarcasm and eye role) Netscape news, MSN news

d. Computer conferencing: allows a group of people to hold a discussion by computer.

i. Members of the group can use the system to post messages to the whole group, and discussions can thus take place over a period of time.

ii. Have the possibility for real time interaction.

iii. The members of the group are in a separate network.

iv. (ask for example, sarcasm and eye role) Ex: First class

e. Audio conferencing: is the simultaneous connection of many different telephone lines.

i. A group of people can have communication with each other by way of the telephone.

ii. (ask for example, sarcasm and eye role) Ex: Microsoft Netmeeting

f. Video conferencing: real time video and audio communication between people in difference locations. 
i. A video camera, a monitor and some features to control them are needed to send and receive the information.

ii. (ask for example, sarcasm and eye role) Ex: A system for videoconferencing is CU-SeeMee

g. Voice mail systems: electronic mail systems for spoken messages.

i. The telephone can also be used to send messages and receive them so a computer is not necessary.

ii. (ask for example, sarcasm and eye role) Ex: IPhone

h. IRC: is a mode of interaction on the Internet in which people are able to communicate synchronistically on different 'channels' from disparate locations.

i. This is text-based, but is possible to send images as an attachment.

ii. (ask for example, sarcasm and eye role) Ex: Microsoft Netmeeting

i. MUD/MOO: Multi User Dungeons/MUD Object Oriented.

i. It is a synchronous system in which users can interact in real time by typing text.

ii. It is virtual reality because it describes objects like rooms or buildings and users that are in the same place that you are.

iii. You are a character in this environment that can take actions by typing commands like walk, whisper, kick, etc.

iv. (ask for example, sarcasm and eye role) Ex: Multiplayer computer game: World of Warcraft

j. Whiteboard environments: are virtual meetings where each participant can use the mouse to draw sketches on the whiteboard.

i. As each user is drawing, every other user connected to the server sees the updates almost immediately.

ii. Most have a chat window where participants can type messages to each other.

iii. (ask for example, sarcasm and eye role) Ex: Microsoft Netmeeting

k. Work flow applications: have intrinsic and interaction rules that embody the business process.

i. Work flow management rules underlie the movement of data from person to machine, control the manner in which the data is processed, and control the way data is stored.

ii. (ask for example, sarcasm and eye role) Ex: Lotus Notes

All of these CMC systems you will need a common computer, a network connection, and special software.

V. Media supported by computer-mediated communication

a. 5 kinds of media are distinguished here

i. Text: (ask for example, sarcasm and eye role) consists of letters, numbers, punctuations, special characters, and controls.

ii. Graphics: (ask for example, sarcasm and eye role) are lines, circles, boxes, shading, fill colors, etc.

iii. Images are still pictures, expressed as the colors of many small individual picture elements (pixels), (ask for example, sarcasm and eye role) this can be a photograph or paintings.

iv. Audio: (ask for example, sarcasm and eye role) consists of sound including voice, music, and special effects. 
V. Video (ask for example, sarcasm and eye role) consists of successive pictures presented sufficiently rapidly to give the appearance of smooth motion. 
Appendix E

Academic Self-Efficacy

Directions: A number of statements which people have used to describe themselves are given below. Read each statement and then circle the appropriate numbers to the right of the statement to indicate how you feel right now.

(1) completely disagree

(2) disagree

(3) some what disagree

(4) neutral

(5) some what agree

(6) agree

(7) completely agree

1. I have the power to make a difference in how things were done in this class.

2. My participation was important to the success of this class.

3. I can help others learn in this class.

4. I can't influence what happens in this class.

5. My participation in this class makes no difference.

6. I can influence this teacher. 


\section{Appendix F \\ Curiosity}

Directions: A number of statements which people have used to describe themselves are given below. Read each statement and then circle the appropriate numbers to the right of the statement to indicate how you feel right now, that is, at this moment.

There are no, right or wrong answers.

Do not spend too much time on any statement but give the answer, which seems to describe how you generally feel.

$1=$ Almost never $\quad 2=$ Sometimes $\quad 3=$ Often $\quad 4=$ Almost always

1. I want to know more....................................... 14244

2. I feel curious about what is happening....................... $14 \begin{array}{lllll}1 & 2 & 3 & 4\end{array}$

3. I am feeling puzzled................................... $\begin{array}{lllll}1 & 2 & 3 & 4\end{array}$

4. I want things to make sense............................... $1 \begin{array}{llll}2 & 3 & 4\end{array}$

5. I am intrigued by what is happening....................... $\quad \begin{array}{lllll}1 & 2 & 3 & 4\end{array}$

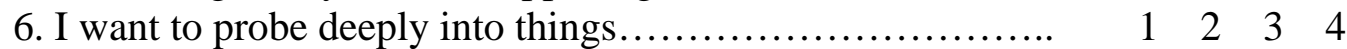

7. I am speculating about what is happening................. $\quad \begin{array}{llllll}1 & 2 & 3 & 4\end{array}$

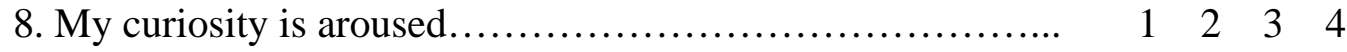

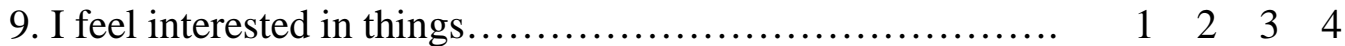

10. I feel inquisitive........................................ 1424

11. I feel like asking questions about what is happening......... $\quad \begin{array}{llllll}1 & 2 & 3 & 4\end{array}$

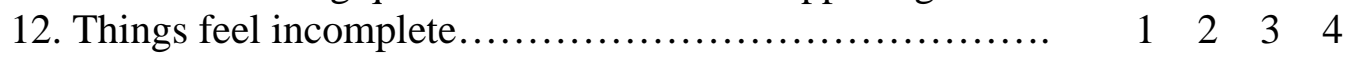

13. I feel like seeking things out........................... $\quad \begin{array}{lllll}1 & 2 & 3 & 4\end{array}$

14. I feel like searching for answers............................ $14 \begin{array}{llll}1 & 2 & 3 & 4\end{array}$

15. I feel absorbed in what I am doing........................ 1425

16. I want to explore possibilities............................ 14254

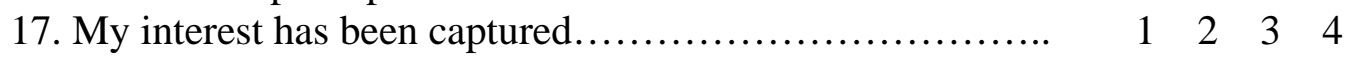

18. I feel involved in what I am doing......................... $1424 \quad \begin{array}{lllll}1 & 2 & 3 & 4\end{array}$

19. I want more information................................ 1425

20. I want to inquire further................................... 1254 


\section{Appendix G \\ Motivation}

Please indicate on the scale below your feelings about studying new content in this class. Circle your answer.

$\begin{array}{lllllllll}\text { Motivated } & 1 & 2 & 3 & 4 & 5 & 6 & 7 & \text { Unmotivated } \\ \text { Excited } & 1 & 2 & 3 & 4 & 5 & 6 & 7 & \text { Bored } \\ \text { Uninterested } & 1 & 2 & 3 & 4 & 5 & 6 & 7 & \text { Interested } \\ \text { Involved } & 1 & 2 & 3 & 4 & 5 & 6 & 7 & \text { Uninvolved } \\ \text { Dreading it } & 1 & 2 & 3 & 4 & 5 & 6 & 7 & \text { Looking forward to it. }\end{array}$




\section{Appendix $\mathrm{H}$ \\ Cognitive Test}

Clearly mark the right answer for each question in the place provided.

1. What is computer-mediated communication (CMC)?

a. Communication between people.

b. Communication between media outlets.

c. Communication between by way of computer networks.

d. Communication between computers.

2. There are an estimated people using the Internet in the U.S.
a. 23,300
b. 233,000
c. $233,000,000$
d. $233,000,000,000$

3. To be synchronous means:

a. To communicate with people at the same time.

b. To communicate with people face to face.

c. To communicate with people at different times.

d. To communicate with people through e-mail.

4. Newsgroups or bulletin board systems are a system that

a. A place on the wall to put flyers.

b. A place on the internet to play games

c. A place in public to have discussions.

d. A place on the internet to have public discussions

5. Computer conferencing is a system that allows
a. People to hold discussions face to face.
b. People to hold activities face to face.
c. People to hold discussions through computers.
d. Computers to hold discussions.

6. Graphics are
a. letters, numbers, punctuations
b. sounds, music, voice
c. successive pictures
d. lines, circles, boxes

7. Images are composed of

a. letters, numbers, punctuations

b. successive pictures

c. lines, circles, boxes

d. still pictures

8. Audio conferencing is a system that is
a. Connection of many different phone lines.
b. Connection of many different computers.
c. Connection of many different televisions.
d. Connection of many different videos.

9. Why does $\mathrm{CMC}$ have unparalleled communication capacities?
a. Very expensive. 
b. Can use only for business.

c. Few modes of communication.

d. Can instantly communicate with people.

10. Video conferencing is a system that is

a. Connection of many different phone lines.

b. Connection of many different video.

c. Connection in real time in different locations.

d. Connection in real time between televisions.

11. Voice mail systems is a system that allows

a. Mail system for spoken messages.

b. Mail system for written messages.

c. Mail system for visual messages.

d. Mail system for mud/moos.

12. Audio consists of
a. Still pictures
b. sounds, music, voice
c. successive pictures
d. lines, circles, boxes

13. IRC are systems that

a. Interaction on the Internet of communication on different channels, from disparate locations.

b. Virtual reality, where you are a character in an environment.

c. Virtual meetings where you can use the mouse to draw.

d. Interactions based on business processing.

14. MUD/MOOs are

a. Interaction on the Internet of communication on different channels, from disparate locations.

b. Virtual reality, where you are a character in an environment.

c. Virtual meetings where you can use the mouse to draw.

d. Interactions based on business processing.

15. Video is
a. letters, numbers, punctuations
b. still pictures
c. successive pictures
d. lines, circles, boxes

16. E-mail is a system that

a. The user produces, sends, and receives mail at a computer.

b. The user only receives mail at a computer.

c. A place where a user can post items.

d. Allows a group of individuals to through media.

17. The World Wide Web is a system that

a. Is a combination of online resources available via word-processor-like documents.

b. Is usually a variety of messages found using a computer.

c. Is a combination of media resources available in video.

d. Is a variety of messages found using media such as television. 
18. Whiteboard environments are

a. Interaction on the Internet of communication on different channels, from disparate locations.

b. Virtual reality, where you are a character in an environment.

c. Virtual meetings where you can use the mouse to draw.

d. Interactions based on business processing.

19. Text consists of

a. letters, numbers, punctuations

b. sounds, music, voice

c. successive pictures

d. lines, circles, boxes

20. To be asynchronous means:

a. To communicate with people at the same time.

b. To communicate with people face to face.

c. To communicate with people at different times.

d. To communicate with people through e-mail.

21. Have you ever had a class that discussed Computer Mediated Communication? Yes No 22. If yes was the main topic of the class CMC? Yes No

23. If no, how many units or class periods was CMC discussed in 
Appendix I

Manipulation Check

Please indicate on the line with an " $x$ " which of the following teachers is represented in the scripted lecture. Only choose one category to identify.

1. The teaching category of incompetence deals with basic skills of teaching that instructors should possess. These behaviors could include the use of monotone, unreasonable rate whether slow or fast, etc (Kearney, et al, 1991). These behaviors demonstrate a lack of competence that can be either in a teacher's knowledge of subject matter or related to their ability to actually teach.

2. The second type of teaching category is indolence. Indolent behaviors are represented by a teacher's disregard for the students. Examples of these behaviors would include rushing through class periods so they can leave early, showing up late, returning papers to students late, etc (Kearney, et al, 1991). These behaviors represent laziness in teacher behavior.

3. The third category of teaching behaviors is offensiveness. These behaviors are actions when teachers show a general tendency to abuse the students verbally. Examples of these behaviors would include humiliating, embarrassing, insulting students, the use of sarcasm etc (Kearney, et al, 1991). The behaviors are offensive and abusive they personally attack the student. These three categories make up the concept of teacher misbehaviors.

4. The fourth category of teaching behaviors is competent. These behaviors are actions when the teachers show positive behaviors in a classroom. Examples of these behaviors are making eye contact, smiling, enthusiasm, knowing the subject, being able to discuss the subject well, and getting students involved in a positive way to the lesson. These behaviors truly represent a competence in teaching.

Demographic information:

Age:

Year, circle one: Freshman

Sex, circle correct answer: $\mathrm{M}$

Sophomore

Junior

Senior

$\mathrm{F}$ 